\title{
Multiple myeloma and persistence of drug resistance in the age of novel drugs (Review)
}

\author{
SABNA RAJEEV KRISHNAN ${ }^{1}$, RITU JAISWAL ${ }^{1}$, ROSS D. BROWN ${ }^{2}$, FREDERICK LUK ${ }^{1}$ and MARY BEBAWY ${ }^{1}$ \\ ${ }^{1}$ Graduate School of Health, Discipline of Pharmacy, University of Technology, Sydney, NSW 2007; \\ ${ }^{2}$ Institute of Haematology, Royal Prince Alfred Hospital, Camperdown, NSW 2050, Australia
}

Received November 11, 2015; Accepted December 17, 2015

DOI: 10.3892/ijo.2016.3516

\begin{abstract}
Multiple myeloma (MM) is a mature B cell neoplasm that results in multi-organ failure. The median age of onset, diverse clinical manifestations, heterogeneous survival rate, clonal evolution, intrinsic and acquired drug resistance have impact on the therapeutic management of the disease. Specifically, the emergence of multidrug resistance (MDR) during the course of treatment contributes significantly to treatment failure. The introduction of the immunomodulatory agents and proteasome inhibitors has seen an increase in overall patient survival, however, for the majority of patients, relapse remains inevitable with evidence that these agents, like the conventional chemotherapeutics are also subject to the development of MDR. Clinical management of patients with $\mathrm{MM}$ is currently compromised by lack of a suitable procedure to monitor the development of clinical drug resistance in individual patients. The current MM prognostic measures fail to pick the clonotypic tumor cells overexpressing drug efflux pumps, and invasive biopsy is insufficient in detecting sporadic tumors in the skeletal system. This review summarizes the challenges associated with treating the complex disease spectrum of myeloma, with an emphasis on the role of deleterious multidrug resistant clones orchestrating relapse.
\end{abstract}

\section{Contents}

1. Introduction

2. Normal plasma cell characteristics

Correspondence to: Professor Mary Bebawy, Graduate School of Health, Discipline of Pharmacy, University of Technology, Level 4, Building 7, PO Box 123, Sydney, NSW 2007, Australia

E-mail: mary.bebawy@uts.edu.au

Abbreviations: MM, multiple myeloma; BM, bone marrow; PCs, plasma cells; $M$ proteins, monoclonal proteins; IMiDs, immunomodulatory agents; $\mathrm{ABC}$ transporters, adenosine triphosphatebinding cluster transporters

Key words: multiple myeloma, plasma cells, combination therapy, multidrug resistant clones, $\mathrm{ABC}$ transporters, relapse, personalized management
3. Pre-malignant plasma cell characteristics - monoclonal gammopathy of undetermined significance

4. Malignant plasma cell characteristics

5. Multiple myeloma

6. Therapy

7. Patient-related predisposing factors complicating diagnosis and treatment in MM

8. Tumor and treatment-associated factors complicating treatment

9. Discussion

10. Conclusion

\section{Introduction}

Multiple myeloma (MM) is the second most prevalent hematological malignancy worldwide, with a median onset of 60 years of age (1-6). MM is currently incurable, albeit clinically manageable and typically manifests with an accumulation of terminally differentiated monoclonal plasma cells (PCs) in the bone marrow (3). It is distinguished from solitary plasmacytoma by the presence of aberrant PCs at numerous skeletal sites $(7,8)$.

MM can be 'secretory' or 'non-secretory' depending on the serum/urine levels of secreted monoclonal immunoglobulin. 'Secretory MM' is characterized by the presence of abnormal levels of monoclonal proteins (M-protein) or paraproteins in circulation and urine. 'Non-secretory' MM accounts for $1 \%$ of all MM cases and lacks the hallmark of increased serum or urine M-protein or paraprotein. Consequently, the diagnosis of non-secretory MM depends rather on an increase in tumor burden and evidence of end organ damage $(9,10)$. The complex spectrum of physiological impairment attributed to MM include lytic bone lesions, osteoporosis, compression fractures, bone pain and ultimately patient immobility. The abundance of malignant monoclonal PCs also severely compromises patient immunity and hematopoiesis (11).

The inclusion of immunomodulatory drugs (IMiDs) as part of high dose chemotherapy together with systemic and cytogenetic prognostic markers have improved patient survival in MM. Thalidomide, and its derivatives are currently approved for use across all phases of MM therapy. These drugs possess immunomodulatory, anti-angiogenic, anti-inflammatory and anti-proliferative capacity (12). Over the past few decades, a 
$30-40 \%$ complete response rate and an increase in median survival of 4-5 years have been achieved with these drugs in combination with auto-transplants in younger de novo patients (13).

Most MM patients respond successfully to initial induction therapy, however, all the patients eventually relapse, forcing a review of the treatment regimen (14). A significant contributor to treatment failure leading to clinical relapse is the emergence of multi-drug resistance (MDR) (15). MDR is the phenomenon whereby the cancer cells become resistant to a wide variety of structurally and functionally unrelated drugs following exposure to a single chemotherapeutic agent (16-18). Existing measures for assessing the clinical state of MM patients include serum markers [immunoglobulins, $\beta_{2}$-microglobulin $\left(B_{2} M\right)$, free light chain assays, creatinine, $\mathrm{C}$-reactive protein (CRP) and thymidine kinase] followed by confirmation with invasive bone marrow biopsy. However, these do not offer a direct measurement of the presence or the evolution of proteins responsible for drug resistance on malignant PCs. MM is characterized by the presence of multiple clones with differing degrees of drug sensitivity at the time of diagnosis. Consequently, despite complex chemotherapeutic regimes (19), therapeutic response is unpredictable and extremely variable with MM patients. Furthermore, bone marrow biopsy cannot assess the patchy tumor infiltrates in multiple sites associated with MM and provides an indirect measure of tumor burden distributed throughout the skeletal system. This impacts the quality of life for the patient and translates to highly heterogeneous patient survival rates ranging from a few weeks to more than 10 years (20).

Aside from the significant physical and emotional costs associated with the emergence of MDR and subsequent relapse, there are also significant financial costs incurred with the management of MDR. The drugs used at relapse are typically novel, costly and with associated side effects. The estimated cost of an effective melphalan, prednisone and velcade regimen approximates $\$ 119,102$ (US), while a novel superior regimen utilizing melphalan and prednisone combined with lenalidomide maintenance can reach as high as $\$ 248,358$ (US) (21). Consequently, MM remains one of the most costly cancers to treat when total treatment costs are considered (21-24).

Here, we review the factors limiting the successful treatment outcome in the complex multiple myeloma clinical setting. We focus on the persistent issue of drug resistant clones in MM and the major role played by ATP-binding cassette $(\mathrm{ABC})$ transporters along with other resistance mechanisms in relapse in the era of novel therapeutics.

\section{Normal plasma cell characteristics}

$\mathrm{MM}$ is a hematological malignancy characterized by the accumulation of aberrant PCs in the bone marrow (25). PCs are terminally differentiated activated $B$ cells retained in the G1 phase of the cell cycle (26). PCs express surface markers that are reflective of their elaborate maturation and differentiation process. PCs typically can be distinguished from naïve B cells by the lack of CD10, CD19 and CD20 expression on their surface (27). Two specific surface antigens on PCs are CD38 and CD138 (28-31). CD38 is an ectoenzyme important in signal transduction, cell adhesion and calcium signaling, and is expressed across all PC developmental stages (28). CD138 is a trans membrane proteoglycan that facilitates cell binding, cell signaling, cell-cell and cell-extracellular matrix interactions (32). Amongst the typical markers expressed on PCs, CD45 is considered an early PC marker (plasma blasts) (27). According to the maturation stages, PCs are grouped into plasma blasts (CD138- CD45 ${ }^{++}$), early PC's $\left(\mathrm{CD} 138^{+} \mathrm{CD} 45^{+}\right)$ and mature PC's $\left(\mathrm{CD} 138^{++} \mathrm{CD}^{-} 5^{-}\right.$or weak $\mathrm{CD} 45$ expression) based on the antigen expression on their surface (5).

PCs are prime mediators of the adaptive immune response $(5,26)$. The development of a normal B cell starts in the bone marrow (BM) and matures following migration into the peripheral lymphatic organs. The maturation process is aided by antigen exposure, dendritic co-stimulatory signals and somatic mutations that ultimately result in high affinity antibody production (3). B cells with high affinity antigen receptors further differentiate into memory cells and plasma blasts. Eventually, highly efficient PCs that survive these processes (long-lived PCs) migrate back to the bone marrow and localize in 'niches', which aid in the further differentiation and longevity of the immune response (3,33-35).

\section{Pre-malignant plasma cell characteristics - monoclonal gammopathy of undetermined significance}

Monoclonal Gammopathy of Undetermined Significance (MGUS) is a benign condition that can precede malignant transformation to MM (36). Clinically, MGUS is characterized by excessive PC growth whilst retaining a stable M-protein profile (37). Serum M-protein levels of $<3 \mathrm{~g} / \mathrm{dl}$, small amounts of monoclonal light chains in urine, the absence of end organ damage, absence of lytic bone lesions, anemia and hypocalcaemia define the pre-malignant condition MGUS (38). The rate of transition from MGUS to MM is $\sim 1 \% /$ year $(36,38)$.

\section{Malignant plasma cell characteristics}

The exact cause of malignant transformation of PCs remains unknown. However, ras mutations are absent in pre- malignant MGUS and are observed in MM (39). It has been suggested that the myeloma clone arises from a pre-switched B cell (40), preconditioned as a result of prior exposure to certain triggers (i.e. viruses, chemicals and radiation). Other reasons proposed are an incompetent immune system, age and a family history of lymphato-hematopoietic cancer (36).

In malignant cells, the genotype is aberrant with frequent chromosomal deletions or hyperdiploidy (chromosomes $3,5,7,9,11,15,19$ and 21) that results in abnormal functions of cell cycle regulatory genes (cyclin D1,D2 and D3) (41). Malignant PCs also present with aberrant phenotypes at diagnosis. Surface markers such as CD56, CD117 and CD20 are found in decreasing order of expression on aberrant PCs. Isolated strong CD56 expression is common in MM and can be used to distinguish MM from MGUS, while CD56 phenotype is said to be associated with a high risk subtype with chromosomal abnormality [t(11;14)] in terms of survival (42-44). Malignant PCs also display an increased expression of various adhesion molecules compared to non-malignant PCs. Fibronectin receptor, very late antigen 4 (VLA-4), the lympho- 


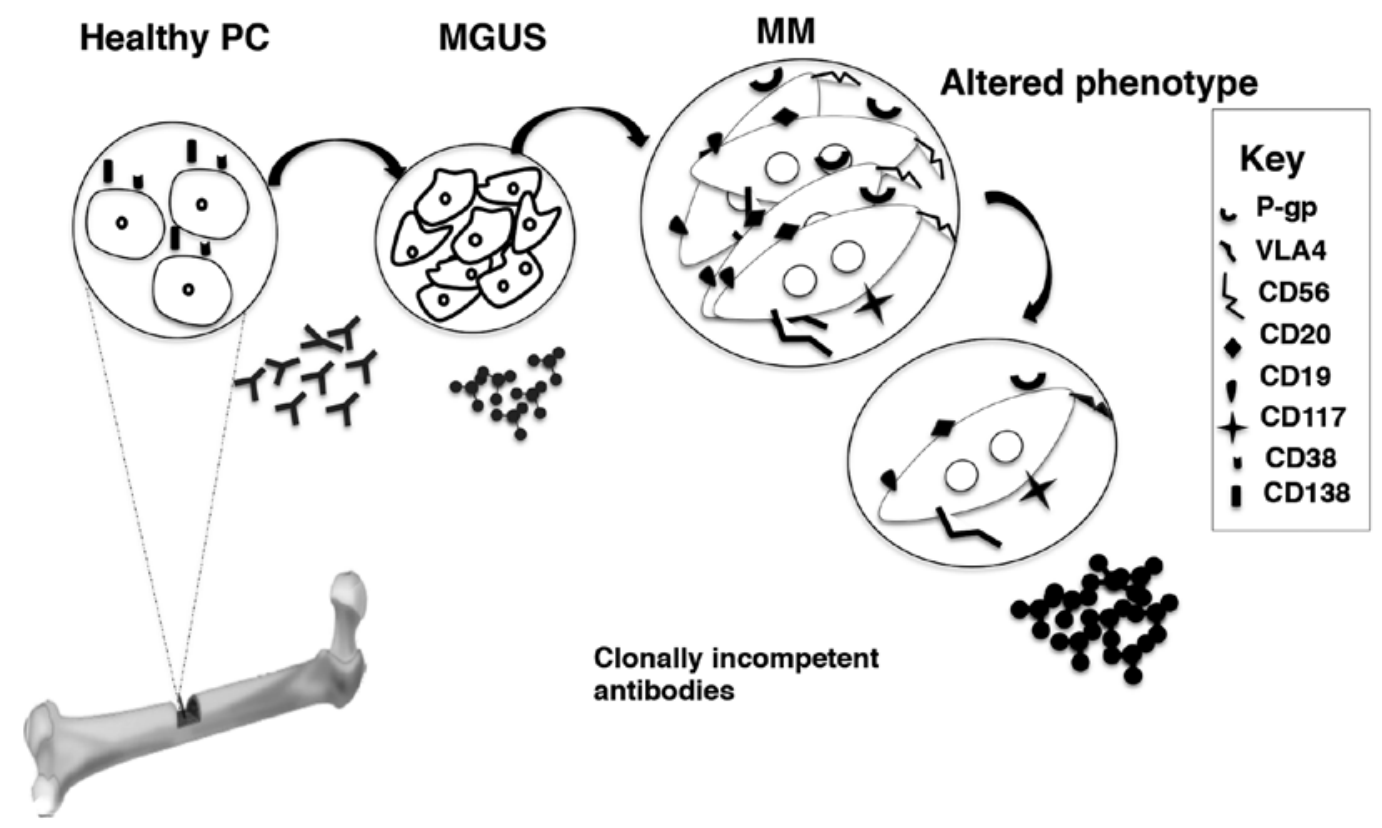

Figure 1. Malignant transformation of PCs: terminally differentiated healthy PCs reside in the bone marrow and typically express CD138 and CD38. Healthy $\mathrm{PCs}$ are major components of humoral response. The pre-malignant condition monoclonal gammopathy of undetermined significance (MGUS) is characterized by the presence serum M-protein and monoclonal light chains in serum and/or urine, however, patients remain well. In the malignant phase, PCs have aneuploidy, altered surface expression and patients experience high serum/urine levels of $\mathrm{M}$ or paraproteins along with other classic MM manifestations. In relapse, the MM initiating cells or 'side population' cells have immature B cell phenotype than the mature PCs. Major signaling pathways are aberrant resulting in the clonotypic MM cells. Clonotypic MM cells are highly proliferative and over express various MDR pumps (P-gp, MRP1 and BCRP) and early B cell marker on their surface and transporters such as vault proteins (LRP).

cyte homing receptor CD44 and neural cell adhesion molecule (N-CAM and CD56) are abundantly expressed on malignant PCs (45). In contrast, VLA-5, the laminin receptor VLA-6, and the vitronectin receptor CD51 are weakly expressed (45). In advanced MM, mature PCs escape the bone marrow niche and are found in circulation (46). Interestingly, only $50 \%$ of the circulating population expresses CD138, which is widely considered to be an exclusive mature PC marker of hematopoietic origin $(27,47)$. Consequently, circulating PCs are also classified according to the presence or absence of CD138 apart from the maturation based classification of normal PCs mentioned above (27). The circulating CD138- PCs are thought to be plasma blasts as they express CD45, CD20, CD19 and human leukocyte antigen (HLA)-class II and more actively proliferating $(5,47,48)$ (Fig. 1).

\section{Multiple myeloma}

Diagnosis. MM is diagnosed when M-protein or paraprotein exceeds $3 \mathrm{~g} / \mathrm{dl}$ in serum or urine (49), when there are $10-15 \%$ aberrant PCs in the bone marrow and by the presence of skeletal lesions $(5,37,50)$. An abnormal ratio of serum $\kappa$ and $\lambda$ free light chains above the normal range of $\kappa / \lambda$ of $0.26-1.65$ provides an alternative criterion if the M-protein status is not conclusive $(9,10,50)$. In the case of 'non-secretory myeloma', $\geq 10 \%$ baseline clonal bone marrow PC provides the main criterion of diagnosis with renal and skeletal manifestations of MM $(9,50,51)$.

Other clinical manifestations alone or in combination are also considered at diagnosis. These include elevated calcium levels or hypercalcemia $>11.5 \mathrm{mg} / \mathrm{dl} />2.65 \mathrm{mmol} / \mathrm{l}$ indicating defective bone physiology, renal insufficiency signified by creatinine $>2 \mathrm{mg} / \mathrm{dl} / 177 \mu \mathrm{mol} / 1$ or more, anemic hemoglobin levels of $<10 \mathrm{~g} / \mathrm{dl}$ or $2 \mathrm{~g} / \mathrm{dl}<$ normal levels or hemoglobin $<12.5 \mathrm{mmol} / \mathrm{l}$ or $1.25 \mathrm{mmol} / 1<$ normal levels, and bone lesions or pain (9). International uniform response criteria by International Myeloma Working Group recommends that amyloidosis and/ or systemic light chain deposition disease (LCDD) should be correspondingly categorized as 'myeloma with documented amyloidosis' or 'myeloma with documented LCDD', requiring confirmation through bone marrow biopsy to ascertain the existence of $\geq 30 \%$ PCs and/or myeloma-related bone disease. Following diagnosis, MM patients are usually placed on induction therapy with conventional or novel agents followed by autologous stem cell transplant depending on eligibility of each patient (52). Response to treatment is subsequently evaluated through regular monitoring of serum and urine M-protein levels by immune fixation and confirmed by periodic bone marrow aspiration (53).

Staging criteria. MM is a highly heterogeneous disease with respect to survival and clinical manifestations (54), hence it is difficult to accommodate every criterion in one staging system (55). In 2005, the International Myeloma Working Group established the International Staging System (ISS) for MM (Table I) (54). Until 2005, MM staging predominantly relied on the Durie-Salmon Staging (DSS) system, which was established in 1975 (56). DSS correlates various biochemical factors with tumor burden for staging of malignancy. This makes it difficult to achieve consensus across various laboratories (57). The advantage of ISS is that it is a statistical model, which emphasizes the duration of survival based on 
the measure of two parameters, $\mathrm{B}_{2} \mathrm{M}$ and serum albumin (55). ISS uses $\mathrm{B}_{2} \mathrm{M}$ as a measure of the rate of myeloma growth with serum albumin indicative of tumor burden $(54,55,58)$. Since its launch, ISS has been validated, is statistically easier to assess and is more robust compared to the DSS system $(55,59)$.

Genotype and multiple myeloma. Myeloma, unlike other hematological malignancies, is uniquely characterized by intricate cytogenetic and molecular genetic abnormalities resonant of epithelial tumors (60). A de novo patient usually presents hyperdiploid with multiple trisomies or hypodiploid with one of several types of immunoglobulin heavy chain ( $\operatorname{IgH})$ translocations (61). The importance of cytogenetic markers and gene profiling on therapeutic decision making is becoming increasingly evident in MM (62).

Chromosomal abnormalities associated with immunoglobulin heavy chain translocations result in abnormal gene regulation in MM (63). Cell cycle regulatory genes are impaired in $\mathrm{MM}$ and the dysregulation of cyclin D1,D2 or D3 is considered to be an initial oncogenic pathway in MM and MGUS (64). $25 \%$ of IgH translocations in MM directly affect cyclin D1 (11q13), cyclin D2 $\mathrm{t}(4 ; 14)$, cyclin D3 $(6 \mathrm{p} 21)$ or musculoaponeurotic fibrosarcoma $(M A F)$ oncogene (c-MAF, 16q23 or $M A F$ oncogene homolog B (MAFB), 20q11 (41,64). The recurrent translocations associated with $\mathrm{MM}$ are $\mathrm{t}(4 ; 14)(\mathrm{p} 16 ; \mathrm{q} 32)$, and $\mathrm{t}(14 ; 16)(\mathrm{q} 32 ; \mathrm{q} 23)$ which are correlated with a negative prognosis (61). Myeloma patients frequently present with chromosomal deletions of $13 q 14$ and 17p13 (63). Several other genetic components such as tumor suppressor genes ( $\mathrm{p} 53$, phosphatase and tension homologPTEN), retinoblastoma protein-Rb protein) and transcription factor, myelocytomatosis viral oncogene homolog $(c-m y c)$ also show abnormalities in MM, however, the exact origin of these genetic and epigenetic changes in the course of MM pathogenesis is not known yet (39).

Recently, the role of short non-coding RNAs (19-25 bp) in MM has been examined (65). A small number of microRNAs (miRNAs) are implicated in MM pathogenesis (65). Pichiorri et al demonstrated distinct miRNA profiles for malignant PCs (MGUS and MM) compared to those of normal PCs. In MGUS, $m i R-21$ and $m i R-106 b \sim 25$ clusters with oncogenic function are upregulated with $m i R-21$ blocking apoptosis (66). $m i R-106 b \sim 25$ has been shown to regulate pro-apoptotic genes and play a role in pathogenesis (67). It is believed that $m i R-21$ and $m i R-106 b \sim 25$ potentially initiate the lymphoproliferative transformation of PCs by hindering apoptosis, promoting survival of malignant cells and predisposing to secondary genetic abnormalities, leading to malignancy (65). Compared to the normal PCs, miR-32, $m i R-17 \sim 92, m i R-21, m i R-106 \sim 2, m i R-181 a$ and $m i R-181 b$ are upregulated in MM. $m i R-15 a$ and $m i R-16-1$ are implicated in regulating tumor proliferation in $\mathrm{MM}$ that are located in 13 q14.3 which coincides with a frequent deletion in MGUS and MM cohort $(65,68,69)$.

\section{Disease presentation}

Systemic monoclonal protein (M-protein or paraprotein). Monoclonal protein (M-protein or paraprotein) production, is a salient feature of secretory MM (70). Based on immunoglobulin heavy chain structure, MM is classified into $\operatorname{IgG}, \operatorname{IgD}$ and $\operatorname{IgE}$ subtypes of which $\operatorname{IgG~MM}$ is most common (11).
Paraproteinemia and an associated hyperviscosity syndrome, arising from elevated systemic M-protein levels are typically associated with MM (11,71). Approximately $25 \%$ of MM patients present with paraproteinuria resulting in renal insufficiency, while $\sim 50 \%$ have renal failure $(11,37,50,72)$ resulting from direct damage and blockage to the kidney (73). Other MM associated renal complications include, myeloma cast nephropathy, amyloidosis, fibrillary glomerulonephritis, immunotactoid glomerular nephritis and light chain deposition disease (72).

Immune incapacity. MM patients are immunocompromized due to the defective hematopoiesis and the aberrant PCs producing clonally incompetent $\mathrm{M}$-proteins. This is in addition to the gradual reduction in immune competence coinciding with late middle age (40). Yaccoby et al proposed limited mobility in the aged population resulting in reduced exposure to antigens as the potential reason for the reduced differentiation rate of the memory B-lymphocytes to PCs $(74,75)$.

The manipulative tumor cells strategically elude the immune watch and facilitate tumor survival. One such mechanism is the phenomenon of 'trogocytosis' in which the surface antigen exchange occurs in lymphocytes creating unique cell phenotypes with specific function (76). The immune synapse facilitates unique cell types to maintain intracellular signaling in $\mathrm{T}$ cell subsets and aid in tumor-induced immune suppression (77). The phenomenon of trogocytosis is more common in $\mathrm{MM}$ compared to other mature B cell malignancies and $\mathrm{T}$ cells are more proficient in acquiring antigens from malignant PCs (78). Impaired immune system in MM patients also leads to recurrent infections with a life-changing impact on patients and care givers (79).

Microenvironment-dependent disease manifestations. One of the characteristic features of MM is the tendency of aberrant PCs to be confined to the bone marrow. Malignant PCs favor a microenvironment analogous to normal longlived PCs $(3,74,75)$ and tend to migrate to peripheral blood only in the terminal stage of the disease $(3,45,74,75)$. These malignant PCs evolve 'autocrine growth supporting loops' at this terminal stage which facilitate microenvironment independent survival (35). The adhesion of MM cell with bone marrow stromal cell orchestrates homing via adhesion to the endothelium, invasion through the subendothelial membrane, and chemotactic migration within the bone marrow stroma $(35,45)$ (Fig. 2).

Aberrant PC interaction with bone marrow stromal cells (BMSCs) and extra cellular matrix (ECM), subsequently alter the normal microenvironment to tumor advantage $(80,81)$. Cytokines such as interleukin 6 (IL6), vascular endothelial growth factor (VEGF), tumor necrosis factor- $\alpha$ (TNF- $\alpha$ ), insulin-like growth factor 1 (IGF1) support the growth of MM cells $(82,83)$. Along with IL6 and IGF1, IL21 promote the tumor survival while VEGF plays a role in MM cell migration with stromal cell derived factor- $1 \alpha$ (SDF-

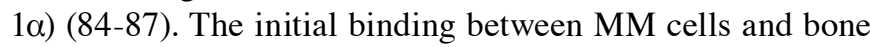
marrow stromal cells is mediated via adhesion receptor integrins (integrin $\alpha 4 \beta 1$, VLA4), through their ligands [vascular cell adhesion molecule 1 (VCAM1)] $(88,89)$. The binding, further, upregulates cytokine and/or chemokine release from 


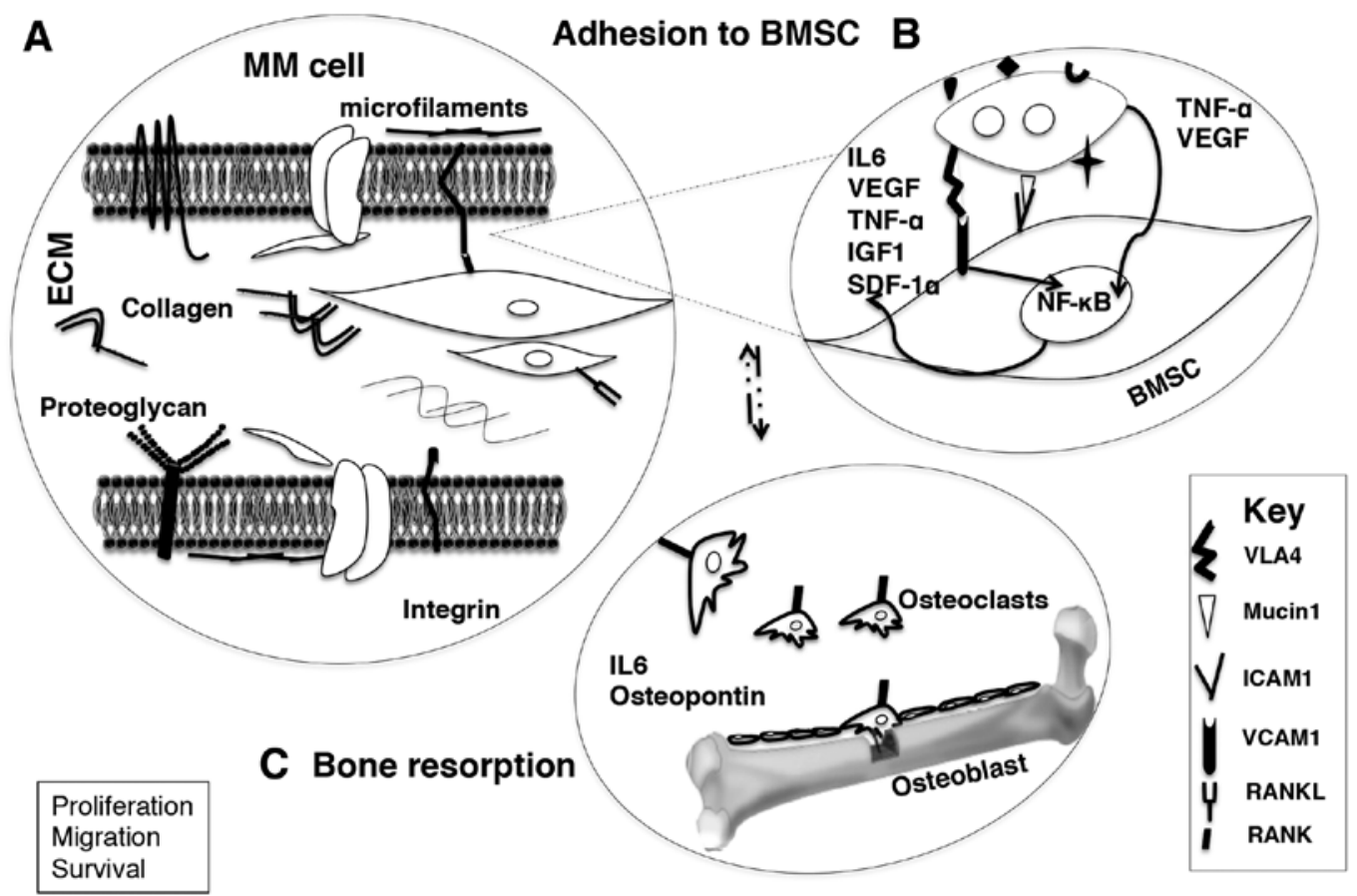

Figure 2. Microenvironment-dependent factors in MM: (A) Aberrant PCs homing to the microenvironment is mediated by integrin mediated adhesion to extracellular matrix (ECM) and bone marrow stromal cells (BMSCs). (B) The growth, survival and migration of an aberrant PC is cytokine mediated and facilitated by the adhesion of aberrant PC to the BMSC. In BMSCs, this contact triggers the cell signaling pathway and nuclear factor- $\kappa \mathrm{B}$ and subsequent secretion of various adhesion molecules/cytokines on both cells. (C) Adhesion to the BMSC is also involved in the bone resorption. MM cells stimulate RANKL expression on BMSCs and reduce osteoprotegerin expression to promote osteoclastogenesis. Adhesion of MM cells to osteoclasts follows with the over production of osteopontin and IL6, supplementing MM cell growth and survival.

stromal cells to the microenvironment (Fig. 2A). In addition, the transcription factor nuclear factor $-\kappa \mathrm{B}(\mathrm{NF}-\kappa \mathrm{B})$ plays a significant role in the initiation of various cell-signaling pathways in MM cell and BMSC following the adhesion $(84,90)$. The adhesion of $\mathrm{MM}$ cell to stroma triggers $\mathrm{NF}-\kappa \mathrm{B}$ and mitogen-activated-protein kinase (MAPK) signaling cascade in BMSC, which in turn results in a change in phenotype of MM, and BMSC with co-expression of adhesion molecules. Subsequently, cytokines secreted from MM cells trigger inflammatory cytokine production and $\mathrm{NF}-\kappa \mathrm{B}$ activation in BMSC (IL6, TNF- $\alpha$ and VEGF). The inflammatory cytokines from BMSCs trigger signaling pathways in MM cells (MAPK, phosphatidyl inositol 3 kinase/protein kinase B (P13/AKT), Janus kinase/signal transducer and activation of transcription 3 (JAK/STAT3) pathways which enhance proliferation, cell cycle modulation and tumor survival via activation of antiapoptotic signals (91-93) (Fig. 2B).

Osteolytic lesions, compromise mobility, can result in spinal cord compression and moderate to severe nerve damage in MM. In fact, morbidity and mortality in MM is mostly associated with osteolytic lesions $(80,81)$. Abe et al (81) demonstrated that peripheral blood mononuclear cell-derived osteoclasts enhance MM cell survival and growth in primary MM, as well as MM cell lines than stromal cells $(75,80,81)$. Receptor activator of nuclear factor $\kappa \mathrm{B}$ (RANK) on the surface of osteoclasts and the ligand (RANKL) expressed on the BMSC activate the osteoclasts while osteoprotegerin on BMSCs a decoy ligand of RANK prevents RANK-RANKL communication (89). Manipulative MM cells stimulate RANKL expression on BMSCs simultaneously reduce osteoprotegerin expression which accordingly promotes osteoclastogenesis.
Consequent adhesion of MM cells to osteoclasts enhances the production of osteopontin and IL6, which augments MM cell growth and survival $(88,89)$ (Fig. 2C).

\section{Therapy}

Treatment of MM typically involves combination chemotherapy including cyclophosphamide or melphalan, a steroid (dexamethasone or prednisolone), a novel agent [e.g. proteasome inhibitor, immunomodulatory drug (IMiDs)] and may be followed by autologous stem cell transplant depending on the age at diagnosis (2). Treatment of progressive MM consists of induction, maintenance and supportive regimens (50). In patients below 65 years of age, autologous stem cell transplant (ASCT) is considered (13). In many cases a single autologous stem cell transplant can result in progression-free survival in comparison with chemotherapy alone (94).

The IMiDs and the proteasome inhibitors (e.g. bortezomib and carfilzomib) have provided significant improvements in survival and quality of life in MM (95). IMiDs are structural and functional analogs of thalidomide that have potent immunomodulatory properties, anti-myeloma activity and better tolerability profiles (96). Thalidomide was the first immunomodulatory agent approved for use in MM. It is highly active against MM, however, is limited by considerable toxicity, particularly in older patients (97). Lenalidomide, an analog of thalidomide, possesses more potent activity with less toxicity and consequently is preferred for use across phases of MM treatment (98).

Thalidomide monotherapy when used for induction therapy produces a low response rate of $\sim 35 \%(99,100)$. In the context 


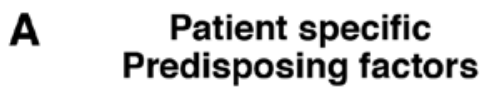
Predisposing factors
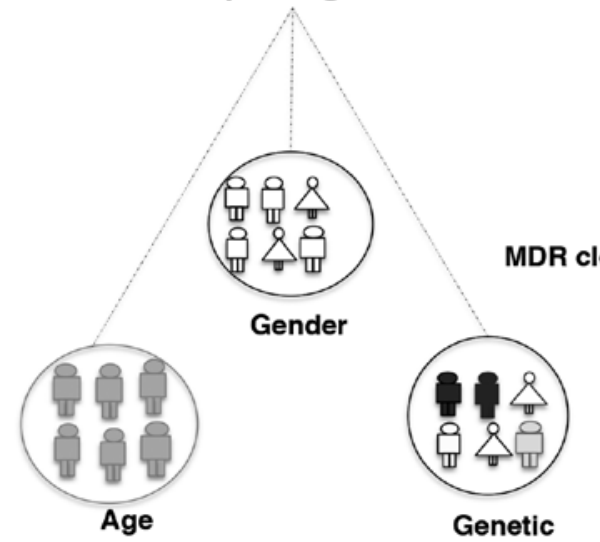

B Tumor specific factors clonal heterogeneity


No routine measures to monitor the
emergence of MDR clones in the bone marrow

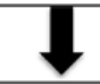

Relapse

Figure 3. Patient and tumor specific factors impacting on predisposition and treatment in MM: (A) The demographic (age, gender and genetics) variables cause relative pre-disposition of MM in patients. The incidence of $\mathrm{MM}$ increases with age and $\mathrm{MM}$ manifestations mimic ageing symptoms. MM is more common in males than females. African Americans are more predisposed for MM in comparison with Caucasians or Asians. (B) Myeloma is incurable despite most patients responding to initial high-dose induction therapy and the introduction of novel class of drugs (proteasome inhibitors, IMiDs). The eventual relapse is a result of vigorous changes in MM biology and the development of drug resistance during the course of treatment. Currently, the emergence of MDR ${ }^{+} \mathrm{MM}$ cells is overlooked in the clinical setting.

of relapsed disease, thalidomide monotherapy results in a median event-free survival of 6-12 months and median overall survival of 14 months (101). Thalidomide's combination with dexamethasone improves the rate to $60-75 \%$ and is associated with a high incidence of grade 3-4 toxicity (102-104). For relapsed MM, the addition of an alkylating agent (cyclophosphamide or melphalan) further increases the response rate to $75-80 \%(105,106)$. In comparison with the response rates achieved using novel agents such as bortezomib or lenalidomide, thalidomide monotherapy is not superlative. In addition, combination of thalidomide with cytotoxic agents such as doxorubicin or cyclophosphamide, improves the response rate and quality of response further. Consequently, a three-combination regimen is more commonly used when thalidomide induction is considered (104). However, for consolidation/maintenance therapy, the impact of thalidomide on therapeutic outcome remains unclear. Results obtained from the British Myeloma Research Council Myeloma IX study demonstrates that thalidomide is associated with shorter post-relapse survival suggesting that thalidomide maintenance may induce drug resistance compromising duration of response and survival especially in patients with high risk genotype $[\mathrm{t}(4 ; 14), \mathrm{t}(14,16)$, $\mathrm{t}(14,20)$, 1q21amp, del(17p)] $(107,108)$.

Other novel agents like thalidomide derivatives (lenalidomide) and proteasome inhibitor (bortezomib) combination chemotherapy increases the overall response rate to $90 \%$ or above (109-112).

A complete remission or complete response (CR) in $\mathrm{MM}$ is clinically defined as negative serum and urine immunofixation, no plasmacytoma and $\leq 5 \%$ PCs in bone marrow for at least 2 months (113), whereas partial response is stated by $>50 \%$ reduction of serum M-protein and $>90 \%$ of Bence Jones protein $(113,114)$.
Defining clinical relapse. The malignant PCs enter a static phase with typically lower levels of proliferative markers such as thymidine kinase, high sensitive CRP marking the remission status of MM patient after successful induction therapy (115-117). However, MM cells eventually overcome this passive phase and become aggressive within a short space of time (118). This complex process is said to include loss of immune regulation, clonal evolution, cytokine deviance, oncogene stimulation and/or tumor suppressor gene anomaly (118). The mechanisms underlying initiation, a prolonged asymptomatic stage, progression and aggressive transformation of PCs are not yet clear (118). The failure of the current chemotherapeutic regimen to eliminate the malignant clone in MM is considered to be one of the major causes of consecutive relapse (118). Relapse from a complete response is clinically defined by the reappearance of the serum or urine M-protein (paraproteinemia), $\geq 5 \%$ bone marrow PCs, new lytic bone lesions and/or soft tissue plasmacytomas, an increase in the size of residual bone lesions and/or the development of hypercalcaemia (corrected serum calcium $>11.5 \mathrm{mg} / \mathrm{dl}$ ) not attributed to another cause $(114,119)$.

\section{Patient-related predisposing factors complicating diagnosis and treatment in $\mathrm{MM}$}

Patient age and gender. The incidence and risk of developing MM increases with age, with predominantly $80 \%$ of affected patients being above the age of $60(1,5,120)$. The classic disease manifestations in MM such as anemia, bone pain and associated fracture and renal involvement imitate the complications associated with ageing process (36). Consequently, patients discount the warning signals, which results in delayed diagnosis, which severely compromises the accessible therapeutic 
decisions for the elderly patients. Myeloma is more common in men than women for reasons yet unknown (5) (Fig. 3A).

Ethnicity. The incidence MM is lowest among those of Asian descent, is intermediate in Caucasians and is highest in African Americans $(25,121,122)$. Various independent studies have suggested that there may be a greater genetic predisposition to MGUS in Africans and African Americans than in Caucasians (123). Although the reason for this genetic pre-disposition is not known, a small number of studies have revealed that the variation in the prevalence of immunoglobulin subtypes and the overexpression of either $\kappa$ or $\lambda$ free light chain ratios in different races may contribute to the differential cytogenetic susceptibility between races (123). The presence of a rare deletion of $193 \mathrm{bp}$ in the long arm of the pseudogene [poly(ADP-ribose) polymerase-allele B] of chromosome 13 (negative prognosis in $\mathrm{MM}$ ) is more frequent in African Americans than Caucasians (69). Although the etiology of MM remains unknown, a family history of hematological disorders, either alone or combined with exposure to certain viruses, radiation and chemicals, is a proposed risk factor (36) (Fig. 3A).

\section{Tumor and treatment-associated factors complicating treatment}

Clonal evolution. Numerous studies have confirmed the presence of tumor-initiating cells (stem cells) in the bone marrow and their role in disease relapse $(48,124)$. The primary bone marrow contain a small population of clonotypic B cells with an immature phenotype (CD138') known as 'side population' or MM initiating cells with stem-cell characteristics besides the malignant 'main population' (48). These cells contain more quiescent cells than 'main population' cells in cell cycle analysis. The MM stem cells or 'side population' (SP) cells are enriched source of cancer stem cells and characteristically show low staining of Hoechst 33342 dye, have high clonogenic potential and possess self renewal capacity $(48,125)$. The SP cells contain hypermutated Ig genes, overexpress members of the ABC transporter family such as permeability-glycoprotein (P-gp), multi drug resistance-related protein 1 (MRP1) and breast cancer related protein (BCRP) much like the stem cells (126). The self-renewal capacity of the clonotypic MM cells is mainly attributed to the abnormal signaling pathways found in MM such as Hedgehog, Notch and Wnt signaling pathways (126).

The overexpression of drug efflux pumps is known to compromise the treatment outcome in MM (124). As mentioned, the side population has high expression of MDR proteins. The inability of chemotherapeutics to eradicate MM clones is a major limitation in MM management and a major cause of relapse (127). The detrimental MM clone is persistent during the remission phase and possess high proliferating potential once activated (118). The presence of drug efflux pumps further adds to the deleterious potential of the aforementioned MM clone and cause inevitable relapse (124) (Fig. 3B).

Multidrug resistance. Primary or acquired drug resistance is a major obstacle in MM therapy. In the past, conventional chemotherapeutic treatment of MM, was primarily focused on alkylator and corticosteroid based regimens (VAD regimen-vincristine, adriamycin or doxorubicin, dexamethasone) (128). The current therapeutic regimen includes IMiDs, proteasome inhibitors to improve outcome in MM patients. However, overexpression of MDR genes, topoisomerases and glutathione transferases mediate drug resistance in MM and many cancers (129). Cell adhesion mediated drug resistance (CAM-DR) and overexpression of anti-apoptotic proteins are typical resistance mechanisms also contributing to relapse in MM $(130,131)$.

Topoisomerase II. Topoisomerase II (topo II) is a $170-173 \mathrm{kDa}$ homodimeric protein involved in DNA replication, recombination and gene transcription $(132,133)$. Topo II is an ideal drug target and anthracyclins (doxorubicin), anthracenedions (mitoxantrone) and intercalating agents (acridines) are the main topoisomerase inhibitors used in MM therapy. These drugs interact with topo II to form a temporary complex, which prevents chromosome segregation and DNA synthesis (129). Point mutations in essential domains of the malignant PCs modify the drug target topo II by epigenetic changes such as hypermethylation at the $\mathrm{CpG}$. Island of promoter region affecting the gene expression (129). Structural changes to topo II ( $\alpha$ to $\beta$ ) also contribute to drug resistance to topo II inhibitors used in MM therapy (129). The sub-cellular localization of topo II is also crucial in determining the drug effectiveness and is governed by the adhesion moleculemediated resistance mechanism in MM (134). Turner et al demonstrated that tumor density plays a role in topo II resistance in such a way that in high density MM tumors, majority of the topo II is transported away from the DNA to the cytoplasm and the drugs fail to form cleavable complexes resulting in poor therapeutic outcome (135).

Glutathione transferases. Glutathione ( $\gamma$-glutamylcysteinylglycine) is a tripeptide thiol present throughout the mammalian organ system specifically in the liver and kidney. Physiologically, glutathione plays a critical role in clearance of xenobiotics, harmful radiations and free radicals $(129,136)$. Glutathione transferases (GST) are a family of detoxification enzymes catalyzing the non-covalent or covalent conjugation of glutathione with the diverse detrimental electrophilic compounds. GSTs also sequester toxic compounds and protect the cells from the oxidative stress through inherent organic peroxidase activity. The cytosolic and microsomal GST forms in humans are differentiated as GST $-\pi,-\alpha$ and $-\mu$ of which GST- $\pi$ form is the most common enzyme. The conjugation with glutathione makes the toxic compounds water soluble facilitating an easy expulsion from the cells. In the malignant status, this effective detoxification mechanism also becomes unfavorable. Active GSTs are either increased in the cell or the expression levels of the isozymes are altered to protect the tumor by catalyzing the toxic chemotherapeutics $(136,137)$. Alkylating agents, melphalan and cyclophosphamide used in myeloma therapy are inactivated by GST catalysis resulting in poor therapeutic outcome (129). In addition, high percentage of co-expression of GST- $\pi$ (82\%) with P-gp which is another class of MDR protein (72\%) in MM relapse is reported by Petrini et al (138). This implicates co-operation of two distinct MDR pathways in coordinating poor therapeutic response. 


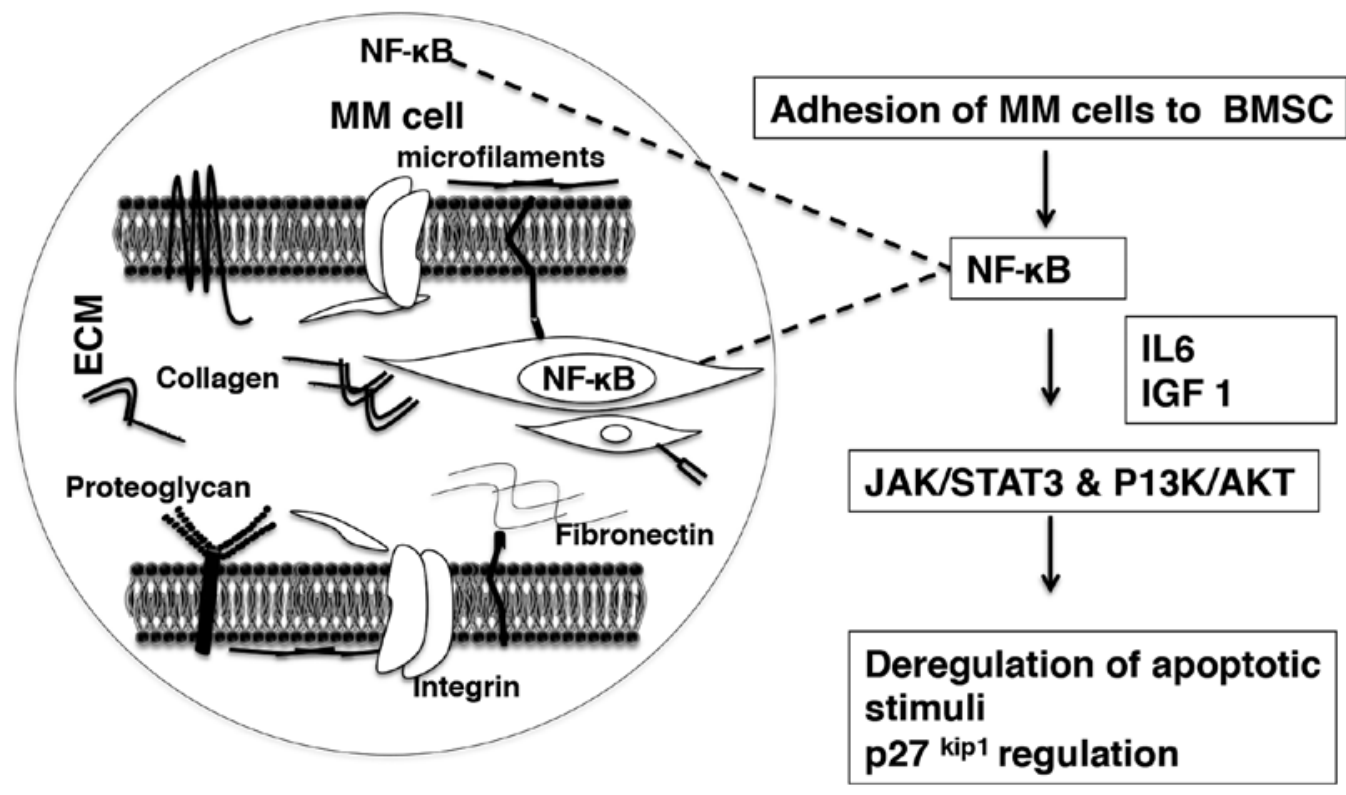

Figure 4. Microenvironment-mediated drug resistance in MM. The adhesion of MM cells to fibronectin in the extracellular matrix (ECM) enhances MM cell survival and growth. The adhesion triggers the deregulation of apoptotic stimuli and facilitates MM growth and survival through NF- $\mathrm{kB}$ pathway activation. The alteration of drug target (topo II), cytokine (IL6 and IGF1) mediated upregulation of cell signaling (JAK/STAT3 and PI3K/AKT) cascades also play a major role in initial drug resistance in MM.

Microenvironment-mediated drug resistance. Apart from microenvironment-mediated pathogenesis mentioned above, components of the bone marrow microenvironment contribute to treatment unresponsiveness in MM $(139,140)$. The microenvironment related resistance mechanisms could be classified as integrin mediated adhesion to ECM (fibronectin) disrupting the apoptotic stimuli through cytokine-mediated upregulation of cell signaling and caspase mediated apoptotic cascade in $\mathrm{MM}$ cell. Microenvironment-dependent drug resistance in MM is considered as a bonus mechanism in MM cells by which the drug resistant cells are selected early on during initial therapy and they later acquire more explicit drug resistance during the course of chemotherapy (141).

CAM-DR. CAM-DR is induced following the interaction of malignant PCs to the ECM (141). Aberrant PCs express a variety of cell adhesion molecules, which function as cellto-cell and cell-ECM through counter receptors. Fibronectin mediated adhesion has been shown to increase the tolerance of MM cell line (RPMI-8226) to chemotherapeutic agents and the induction of drug resistance in MM cells by suppressing apoptosis (142). Integrin molecules such as the VLA4, VLA5 and their respective receptors govern this resistance mechanism. The integrin molecules act as extrinsic factors eliciting intracellular response through focal adhesion points that stimulate signaling pathways and cytoskeletal modification (141). Damiano et al (142) demonstrated that the initial integrin mediated adhesion to fibronectin enhances MM cell survival and protects against apoptotic stimuli from doxorubicin and melphalan aiding tumor survival (141). The mechanism of CAM-DR can also be through blocking a specific element of the caspase mediated apoptotic pathway as shown by Shain and Dalton (141) in MM cell line RPMI-8226. The study showed direct inhibition of mitoxanthrone-induced caspase- 3 and -7 cleavage. Once adhered to fibronectin, the cancer cells use the microenvironment in a number of ways to develop de novo drug resistance such as overexpression of cell cycle regulatory protein $\left(\mathrm{p} 27^{\mathrm{Kipl}}\right)$, alterations to drug target and by facilitating integrin mediated cell signaling and cytoskeletal reorganization (Fig. 4).

Cytokine-mediated drug resistance. The MM cell-BM microenvironment cytokines regulate apoptosis and MM cell survival through their participation in P13K/AKT and JAK/ STAT3 signaling pathways (84). Novel and conventional chemotherapeutics in MM target the caspase-mediated apoptosis pathways. Caspase- $8 / 3$ mediated death receptor pathway (IMiDs, melphalan) and caspase-9/3 mediated mitochondrial intrinsic pathway (dexamethasone) follow subsequent poly-(ADP-ribose) polymerase (PARP) cleavage resulting in apoptotic death of MM cells (92,143-145). The proteasome inhibitor class (bortezomib) targets both caspase-8/3 and caspase-9/3 pathways (146). The IL6 mediated activation of JAK/STAT3 signaling cascade results in upregulation of myeloid cell leukemia sequence 1 (MCL1) and $\mathrm{B}$ cell lymphoma/leukemia family (Bcl-XL) leading to dexamethasone resistance (147). P13K/AKT signaling and NF- $\mathrm{KB}$ activation in MM cells are coordinated by IL6 and IGF1 by inducing inhibitors of drug-induced apoptosis resulting in treatment unresponsiveness and eventual survival of the tumor $(148,149)$ (Fig. 5).

In conclusion, the MM cell-ECM interactions are a foundation for the de novo resistance to chemotherapeutics and thus pave the path for more mutative transformations or acquisition of classical MDR mechanisms during the course of treatment $(141,142,150)$ (Figs. 4 and 5).

Drug efflux. Cancer cells often develop cross-resistance (to a large variety of chemically and pharmacologically unrelated drugs leading to the phenomenon of multiple (or multi-drug) 


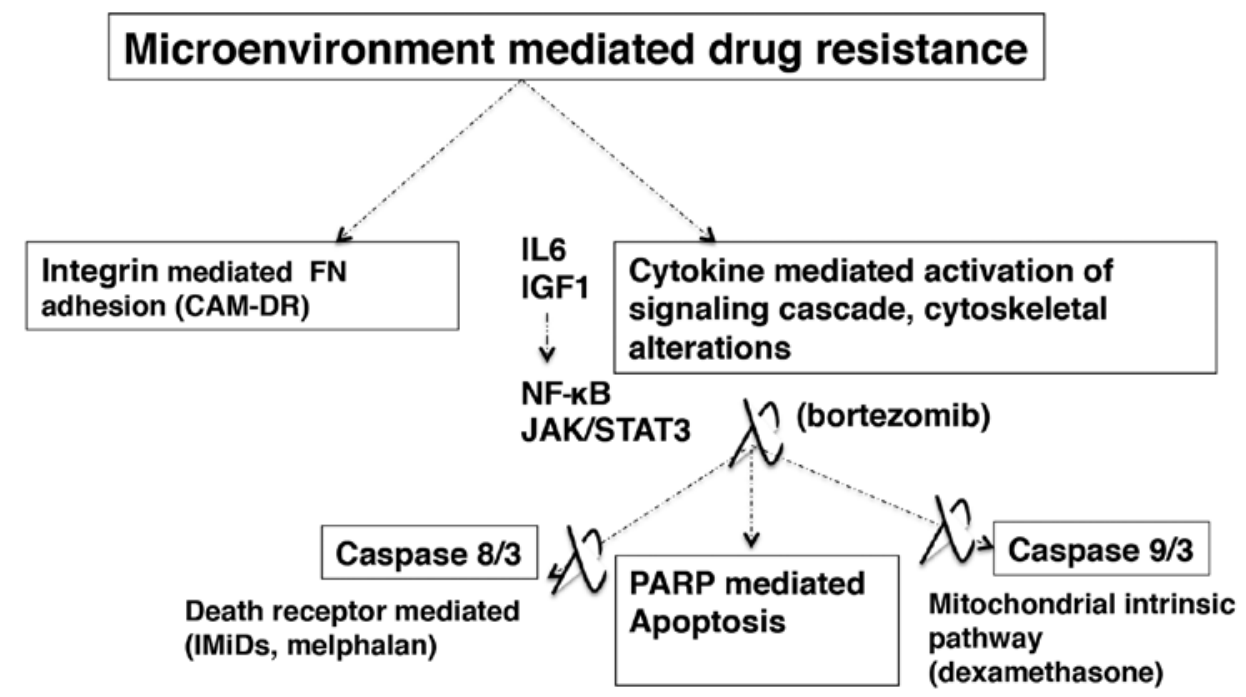

Figure 5. Microenvironment-mediated drug resistance pathways in MM: cell adhesion-mediated drug resistance and cytokine-mediated cell signaling cascade activation contribute to treatment failure in both conventional and novel therapies. Fibronectin-mediated adhesion to the ECM components trigger the cell cycle regulatory proteins $\left(\mathrm{p} 27^{\mathrm{kipl}}\right)$ limit therapeutic success with doxorubicin. Death receptor-mediated apoptotic (caspase-8/3-IMiDs, melphalan) and mitochondrial intrinsic pathways (caspase-9/3, dexamethasone) and proteasome inhibitor targets both these pathways. Cytokine (IL6 and IGF1) activate NF-KB and JAK/STAT3 pathways, disrupting the apoptotic death of tumor cells.

A
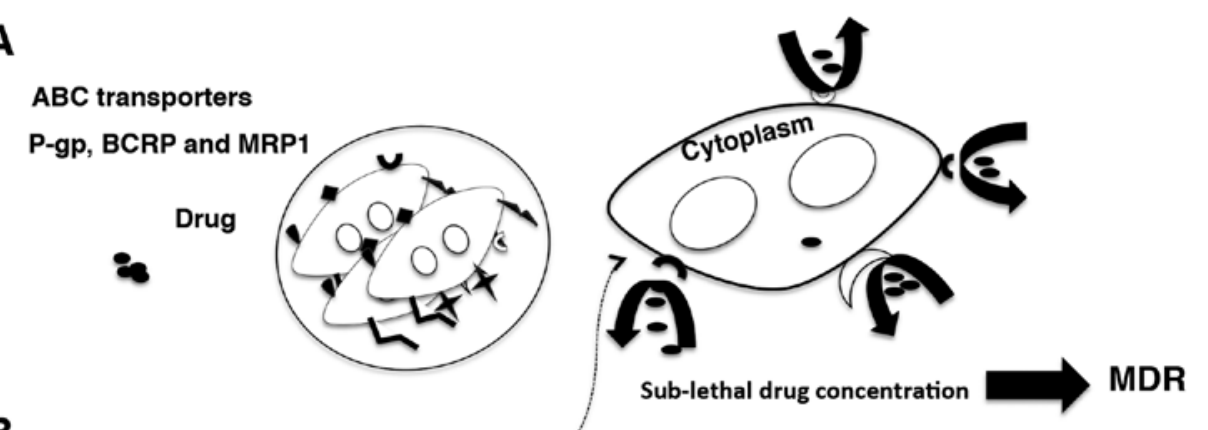

Vault proteins

LRP
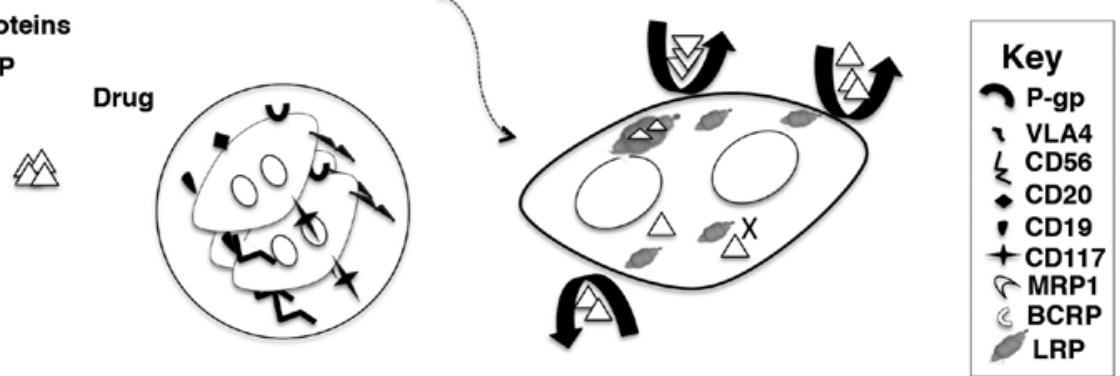

Figure 6. MDR proteins contributing to MM relapse: (A) The $\mathrm{MDR}^{+} \mathrm{MM}$ clones characteristically overexpress the ABC transporters and the vault proteins similar to the stem cell populations. ABC tranporters maintain intracellular sub-lethal concentration of the drug resulting in relapse. (B) Vault proteins (LRP), efflux out or sequester its substrate drugs and prevent the entry to the nucleus, which result in treatment failure and MM relapse. In addition, the transporters cause high systemic drug concentration causing serious side effects in patients with renal insufficiency.

resistance (MDR) (17). MDR is mainly attributed to the overexpression of ATP-dependent efflux transporters belonging to the ABC superfamily (17) (Fig. 6). The overexpression of the ATP binding cassette $(\mathrm{ABC})$ transporters on the plasma membranes of malignant PCs contribute to MDR in MM. P-gp, MRP1 lung resistance protein (LRP) and BCRP are all members of the ABC superfamily of membrane transporters and mediate MDR in MM through their drug efflux capacity (130).

In MM therapy, maximal response rates and improved survival is achieved through combination thalidomide therapy.
Combination chemotherapy is however compromised by the overexpression of the multidrug transporters (P-gp, MRP1, BCRP and LRP) on malignant cells, which maintain intracellular drug accumulation deficits in resistant cells. Although there is no current evidence to suggest that thalidomide itself is a substrate of the these drug efflux pumps, the drugs used in combination as part of the recommended regimens are themselves substrates of one or more of these efflux transporters (Table II) (151-166). This contributes to compromised therapeutic effects, reduced rates of response and overall survival of the tumor. 
Table I. Current International Staging System (ISS) in multiple myeloma.

\begin{tabular}{|c|c|c|c|c|c|c|}
\hline $\begin{array}{l}\text { ISS } \\
\text { stage }\end{array}$ & & & Criteria & & & $\begin{array}{l}\text { Median survival } \\
\text { in months }\end{array}$ \\
\hline I & $\begin{array}{l}\text { Serum } \beta \\
\text { Serum a }\end{array}$ & $\begin{array}{l}\text { bulin } \\
.5 \mathrm{~g} / \mathrm{dl}\end{array}$ & & & & 62 \\
\hline II & $\begin{array}{l}\text { Neither } \\
\text { Or } \\
\text { (i) Serur } \\
\text { (ii) Seru }\end{array}$ & $\begin{array}{l}\text { stage I } \\
\text { globul } \\
\text { gglobu }\end{array}$ & $\begin{array}{l}/ 1 \text { and ser } \\
5.5 \mathrm{mg} / \mathrm{l}\end{array}$ & $\begin{array}{l}<3.5 \mathrm{~g} / \\
\text { of serur }\end{array}$ & level & 44 \\
\hline III & Serum $\beta$ & bulin $\geq$ & & & & 29 \\
\hline Drugs & & P-gp & MRP1 & BCRP & LRP & References \\
\hline Melph & & + & + & - & + & $(152-154)$ \\
\hline Lenalic & & + & - & - & $\mathrm{a}$ & $(155-157)$ \\
\hline Bortez & & + & + & - & $\mathrm{a}$ & $(158,159)$ \\
\hline Thalid & & - & - & $\mathrm{a}$ & $\mathrm{a}$ & (160) \\
\hline Predni & nisolone & + & - & $\mathrm{a}$ & $\mathrm{a}$ & $(161,162)$ \\
\hline Doxor & & + & + & + & + & $(163,165,166)$ \\
\hline Idarub & & + & + & - & $\mathrm{a}$ & $(164,167)$ \\
\hline
\end{tabular}

${ }^{\mathrm{a} I n s u f f i c i e n t}$ published data to comment.

P-gp. The $A B C B 1$ gene located on the long arm of chromosome 7 encodes $170 \mathrm{kDa} \mathrm{P}-\mathrm{gp}$ (17). It is a cell surface protein distributed throughout the human body and is typically found in pharmacological interfaces protecting the cell from carcinogen or xenobiotic influx (17). It has been established that an excessive amount of $A B C B 1$ leads to MDR in many cancers (17). P-gp mediated drug efflux sustains a sub-lethal amount of drug concentration in the intracellular environment enabling the cancerous cell to evade the toxic chemotherapeutic insult resulting in the eventual survival (17).

The main components of conventional induction regimen in $\mathrm{MM}$, the vinca-alkaloid (melphalan), anthracyclines (doxorubicin, daunarubicin) are common substrates of ABC transporters such as P-gp or MRP1 (Table II). Chemotherapeutic resistance in $\mathrm{MM}$ patients is frequently associated with the overexpression of P-gp (167). At least 5\% of cases of untreated MM presents with P-gp which can compromise the induction therapy outcome significantly (168). In addition, the circulating $\mathrm{B}$ cells or the 'side population' in MM express P-gp comprising the resident MDR clone, which leads to MM relapse (169). Nuessler et al also reported that $33 \%$ of patients at relapse or progressive MM are positive for functional P-gp (170).

Several in vitro and in vivo pharmacogenomic and pharmacogenetic studies have revealed genetic polymorphisms of the ABC transport proteins as clinical MDR facilitators in MM. These polymorphisms show diverse function and manifestation across different ethnicities and patient cohorts (171-173). Fifty single nucleotide polymorphisms (SNPs) and 3 insertion/deletion polymorphisms have been identified for P-gp. Of these, three (rs1045642, rs2032582 and rs1128503) were found to have potential therapeutic impact in MM $(171,172)$, though, only rs1045642 $\left(\mathrm{C}_{3435} \mathrm{~T}\right)$ showed correlation to the overall survival in MM. Minimal linkage disequilibrium was shown for the other two SNPs (171). It is believed that rs1045642 may alter the substrate specificity and influence therapy in MM (173). However, the statistical comparison within the MM patient group of Northern Irish ethnicity showed that although rs1045642 had an influence on overall survival, it was insignificant in statistical comparisons between healthy controls and MM patients (173). Another study involving 115 post-transplant MM patients investigating $\mathrm{C}_{3435} \mathrm{~T}$ polymorphism reported that $\mathrm{C} / \mathrm{T}$ and $\mathrm{T} / \mathrm{T}$ genotypes showed a longer overall survival than $\mathrm{C} / \mathrm{C}$ genotype under dexamethasone, adriamycin (doxorubicin) and vincristine (VAD) treatment regimen (174).

$M R P 1$. MRP1 is a $190 \mathrm{kDa}$ protein coded by the $A B C C 1$ gene and located on the plasma membrane of both normal and malignant cells (175). Specifically, in a cell, MRP1 transports multiple organic anions (some glutathione conjugates) protecting against oxidative stress and is reliant on the intercellular glutathione levels for anthracycline transport (176-178). MRP1 gene overexpression results in clinical MDR in patients treated with natural agents such as anthracyclines and vinca-alkaloids $(175,179)$. Abbaszadegan et al reported frequent detectable MRP1 mRNA in MM (100\%) (167). $\mathrm{MRP}^{+\mathrm{ve}}$ cells have been shown to accumulate lower amounts 
of drug relative to $\mathrm{P}-\mathrm{gp}$, potentially due to their dependence on glutathione metabolism $(130,179)$. The presence of the polymorphism, MRP1/R723Q (p.Arg723Gln) results in changes in the physico-chemical properties (size and polarity) of the protein, and this structural change significantly increase time to progression, progression-free survival and overall survival in a group of MM patients treated with velcade and pegylated liposomal doxorubicin (178). It is postulated that the variance in capacity of MRP1/R723Q isoform in trafficking and expression may be the cause of the antitumor effect of anthracyclins in this study (178). The MRP1 expression and its prognostic significance in MM or in cancer in general is comparatively less studied than P-gp (180).

$B C R P$. Breast cancer resistance protein is another $\mathrm{ABC}$ transporter family member with a molecular weight of $72 \mathrm{kDa}$ typically expressed at pharmacological barriers $(181,182)$. Structurally, BCRP encoded by the $A B C G 2$ gene, consists of a single nucleotide binding domain (NBD) and one trans membrane domain (TMD). Consequently, BCRP requires at least two NBDs to function as a drug efflux pump and usually exists as an oligomer (183). BCRP was initially described in MCF-7/AdVrp human MDR breast cancer cell line that did not express P-gp or MRP1 (184,185). In MM, BCRP shows impaired function and is not associated with drug resistance in de novo patients (184). However, BCRP is closely associated with the compounding problem of clonogenic potential of MM cells leading to relapse. The 'MM stem cells' or 'side population' (Hoechst 33342 low staining) have higher BCRP mRNA levels and functional activity compared to the rest of the MM cells (main population) (186). Functional BCRP expression in $\mathrm{MM}$ is inversely proportional to promoter methylation in $A B C G 2$ gene in such a way that unmethylated promoter site results in moderate or high BCRP (ABCG2) expression (187). Numerous polymorphisms for BCRP have been reported in literature (V12M, Q141K, F208S, S248P, F431L, S441N and F489L) however they have not been linked to MM yet (188).

Major vault protein (LRP). LRP is a 110-kDa protein expressed in the kidneys, adrenal glands, heart, lungs, muscles, thyroid, prostate, bone marrow and testis. Most vaults are complex ribonucleoprotein particles comprising two large molecular weight proteins and a small RNA in addition to the $110 \mathrm{kDa}$ LRP. They are mostly present in cytoplasm, with a small fraction present in the nuclear membrane and nuclear pore complex (189). They are assumed to translocate substances across the nucleus and cytoplasm and are said to be involved in MDR $(130,190)$. Raaijmakers et al reported the prevalence of LRP in untreated MM patients (153). This study established the relevance of LRP as an independent predictor in comparison with current markers ( $\mathrm{PC}$ labeling index, serum $\mathrm{B}_{2} \mathrm{M}$ or lactate dehydrogenase level) for therapeutic response and survival in MM patients treated with melphalan (melphalan and prednisone) (153). Thus, screening for LRP prior to treatment to identify the positive population is recommended in therapeutic design in de novo MM to circumvent LRP mediated drug resistance (153). There are currently more than 100 polymorphisms identified for LRP (191). LRP expression rather than polymorphic state have been correlated with therapeutic response (192-195).
Circumvention of MDR. In the past few decades, substantial research has focused on the development and trial of agents, which can reverse the drug efflux capacity of $\mathrm{ABC}$ transporters, in particular P-gp in cancer $(15,130,196,197)$. Indeed, the pharmacological inhibition of P-gp activity has been a major focus in many MM clinical studies (198). In an attempt to circumvent acquired MDR, several inhibitors have been used to improve treatment outcome of patients with MM (16,199-201). The cyclosporin A reversal effect has been evident in phase II studies with MM and acute myeloid leukemia, although phase III clinical trials failed to give the expected response in progression-free survival and overall survival (197). Since the initial successful clinical trials, verapamil and cyclosporin were combined with vincristine, adriamycin and dexamethasone (VAD) in MM, however, these have had disappointing results mainly due to lack of improved efficacy or dose related toxicity $(15,196,197)$.

In conclusion, management of $\mathrm{MM}$ relies on combination therapy and different drug resistance mechanisms, topo II $\alpha$ and GST- $\pi$-dependent resistance, specifically the drug efflux pathways pose a significant challenge in MM clinical setting. Conservative regime in MM, are mostly substrates of ABC-transporters, topo II $\alpha$ and GST- $\pi$-dependent resistance mechanisms (170). Recent studies have reported that the novel agents are also substrates of ABC transporters specifically P-gp (154,157).

\section{Discussion}

Herein, we explored the relevant innate and acquired challenges associated with the therapeutic management of MM including the role of MDR in therapeutic failure. Many cases of MM with late middle age onset fail to be accurately diagnosed early as recurrent infections, tiredness and bone/joint pain is often associated with normal ageing-related complications.

MM is currently an incurable and chronic disease, with 'non-secretory myeloma' exclusively dependent on frequent bone marrow aspiration for the assessment of molecular, cytogenetic markers including aberrant PC population, and categorizing complete response. Secretory myeloma is partially dependent on bone marrow aspiration for the confirmation of the clinical status (9). This is largely because the malignancy is restricted to the bone marrow and is rarely seen in peripheral blood (202). Current risk stratification in MM is also primarily dependent on cytogenetic markers and is assessed using invasive bone marrow biopsy. Nevertheless, the BM biopsy does not provide a sensitive assessment of genetic abnormalities in multiple tumor sites throughout the skeletal system of MM patients. Therefore, even invasive biopsy is not comprehensive in risk profiling patients with MM.

The current ISS, although, presents with distinct advantages over its predecessors, the precise indication of the higher ISS stage (stage III) is inconclusive in terms of whether it suggests tumor burden/aggressiveness or the level of end-organ damage or both (55). There are several reliable systemic markers present for prognosis, like $\mathrm{B}_{2} \mathrm{M}, \mathrm{M}$-protein, however these markers are insufficient in gauging the transition from the indolent phase of MM to an aggressive disease state (118). In the case of 'non-secretory myeloma', diagnosis and prognosis are further limited as it lacks the typical hallmark of the disease. 
$\mathrm{T}$ cells proficiently acquire antigens from MM cells over any other cell type and create novel cell types through trogocytosis (76,77). It is not understood clearly if the novel $\mathrm{T}$ regulatory cell types provide new ligands for receptors and regulate signaling pathways, however, this mechanism enables the malignant PCs to effectively evade the immune system recognition and thereby stimulate tumor growth (203).

We have very little understanding regarding the intricate cycle of dormant and malignant phase of PCs in MM or in other words how PCs escape the plateau phase in the remission status and become aggressive again in relapse. This phenomenon underlines the fact that even aggressive therapy is not successful in eliminating the neoplastic origin of MM (118). As discussed, the MM stem cell population (SP cells) and circulating CD138- PCs are said to have an aggressive proliferative and dissemination capacity $(5,27)$. In addition, they characteristically have self-renewal potential and overexpress the ABC transporters on their surface (124). The persevering MM clone with MDR phenotype potentially lead to treatment failure and currently this aspect is not routinely monitored in the clinical setting. Another complicating aspect of MM is the high heterogeneity in survival amongst patients. MDR phenotype, genetics of MM, including specific IgH translocations and individual immune profiles are potential players with a role in the disparity in survival amongst MM patients. Present systemic markers do not assist greatly in risk stratification, thus, it is more reliant on the cytogenetic markers in this aspect. Therefore, inclusion of more systemic markers, alone or in combination that would aid in early detection, tailor an individualized approach to optimize a prognostic surveillance at diagnosis and after primary surgery is highly recommended in MM (204-207).

The derivatives of thalidomide (IMiDs) have improved overall survival and have increased the cost of treatment significantly. However, in a phase 1 clinical trial conducted in 2011, involving 21 patients with refractive myeloma who were treated with lenalidomide and temsirolimus (mTOR pathway inhibitor-CCI-779), a high concentration of the drug was detected in the blood causing toxicity. The patients experienced unusual side effects such as electrolyte imbalance, rashes, fatigue, and neutropenia. Further investigation of the pharmacokinetic profiles of CCI-779 and lenalidomide suggested a drug-drug interaction, hinting that the disposition of CCI-779 is arguably mediated by CYP3A4/5 and P-gp (208-210). The clinical trial assessed toxicity or adverse effects and response to treatment by serum and urine $\mathrm{M}$-protein quantification every four weeks. There was only limited documented clinical evidence suggesting lenalidomide and P-gp interaction and this possibility was investigated through in vitro studies to determine whether lenalidomide can be transported by P-gp. The in vitro studies proved that lenalidomide is actively transported by P-gp and this effect was reversed by CCI-779 and verapamil. In addition, $A B C B 1$ silencing RNA or short interfering RNA (siRNA) knockdown studies in vitro also showed more lenalidomide uptake, supporting lenalidomide and P-gp drug-drug interaction (154).

In light of emerging studies that these novel drugs that have been incorporated to $\mathrm{MM}$ therapeutic management are substrates of $\mathrm{ABC}$ transporters, the situation warrants a re-evaluation of the manipulative power of MM cells (154). It is evident that opting for more aggressive chemotherapy has brought some promise of prolonging remission and survival in MM. However, this recent study serves as a reminder of aggressive chemotherapy pitfalls of side effects, toxicity and eventual development of MDR phenotype in patients (211). More importantly out of the innate MM complications contributing to treatment failure, MDR is an element that can be modulated and targeted, which, therefore invites specific attention.

The role of polymorphisms in $A B C B 1$ and $A B C C 1$ in both the predisposition to disease and the therapeutic outcome of MM have in recent years been studied extensively. The three most common MDR1 SNPs include $2677 \mathrm{G}>\mathrm{T} / \mathrm{A}$ in exon 21 (RefSNP ID: rs2032582), 3435C $>\mathrm{T}$ in exon 26 (RefSNP ID: rs1045642) and 1236C $>\mathrm{T}$ (RefSNP ID: rs1128503) in exon 12 . The $2677 \mathrm{G}>\mathrm{T} / \mathrm{A}$ polymorphism translated into an amino acid exchange from Ala to Ser or Thr at codon 893, affecting the intracellular region of P-gp between trans membrane 10 and 11 (212). Both $3435 \mathrm{C}>\mathrm{T}$ and $1236 \mathrm{C}>\mathrm{T}$ are synonymous SNPs. The $3435 \mathrm{C}>\mathrm{T}$ mutation results in a change from cytosine to thymine that translates to isoleucine. It is found in the second ATP binding domain, located between the Q-loop and the second signature motif on the intracellular side of the protein. This SNP is associated with altered MDR1 expression (213). 1236C $>\mathrm{T}$ affects the intracellular region of P-gp between the first A-loop and Walker A motif (212) and translates into a glycine residue. These three polymorphisms are and comprise the most common MDR1 haplotype (212). microRNAs, $-m i R-15 a, m i R-16-1$, and $m i R-17-92$ are also shown to play a role in the heterogeneity in the clinical outcome of MM $(65,68)$.

In terms of the therapeutic outcome, Buda et al investigated the prognostic role of MDR1 in the outcome of $115 \mathrm{MM}$ patients treated with DAV (dexamethasone, doxorubicin and vincristine) followed by autologous stem cell transplant. This study showed that the $\mathrm{C}_{3435} \mathrm{~T}$ polymorphism was prognostic with patients with the $\mathrm{C} / \mathrm{T}$ and $\mathrm{T} / \mathrm{T}$ genotypes demonstrating a longer overall survival compared to those with $\mathrm{C} / \mathrm{C}$ genotype. The same polymorphism was again found to be associated with a longer time to progression and progression-free survival in relapsed and/or refractory MM patients treated with pegylated liposomal doxorubicin in combination with bortezomib (178). The T allele in SNP G2677T/A is likewise associated with a better response to DAV (214) and a better overall survival in MM (215).

The single-nucleotide polymorphism in MRP1 (rs4148356, $\mathrm{R} 723 \mathrm{Q}$ ) has also been shown to impact on the clinical outcomes of MM patients (178). The MRP1 mutation Arg723Gln has an effect on the protein expression and trafficking, significantly reducing MRP1-mediated resistance to a wide spectrum of drugs. The presence of $\mathrm{R} 723 \mathrm{Q}$ results in extended time to progression, progression-free survival and overall survival in MM patients. This has been ascribed to the differential ability of the isoform in trafficking glutathione and/or regulating its expression (178). It is currently unknown whether polymorphisms of BCRP play a role in MM treatment outcome (216).

The integrin mediated (CAM-DR) drug resistance mechanism is considered to enable MM cells to survive the initial drug toxicity, which in the course of therapy aids in selective expression of classical drug resistance pathways such as ABC-transporter overexpression in MM cells $(65,68,142)$. 
Current measures of therapeutic response rely on invasive bone marrow biopsy, immunofixation, serum protein electrophoresis, quantitation, measurement of free light chain and CT/MRI scans (217). A full blood count, biochemistry screen, $\mathrm{B}_{2} \mathrm{M}$ and light chain assays are other prominent systemic markers along with radiology used for staging, diagnosis and monitoring in MM $(1,58)$. None of the above markers, however, provide a direct assessment of the emergence of MDR or detect the expression and evolution of resistance markers, polymorphic variants of resistance markers or nucleic acid signatures, which may contribute to disease progression and individual therapeutic responsiveness.

\section{Conclusion}

Cancer biology in general is an intricate process, especially in MM, where individual immunological and tumor profiles change dynamically during the course of treatment. Despite our knowledge of the MM landscape, the intrinsic challenge of heterogeneity provides a significant complication in the management of MM, necessitating individualized analysis of MM pathogenesis and routine monitoring of evolution of drug resistance.

\section{References}

1. Malpas JS: Management of multiple myeloma. BMJ 2: 163-165, 1969.

2. Kyle RA and Rajkumar SV: Treatment of multiple myeloma: A comprehensive review. Clin Lymphoma Myeloma 9: 278-288, 2009.

3. Katz BZ: Adhesion molecules - The lifelines of multiple myeloma cells. Semin Cancer Biol 20: 186-195, 2010.

4. Barlogie B, Alexanian R and Jagannath S: Plasma cell dyscrasias. JAMA 268: 2946-2951, 1992.

5. Reid S, Yang S, Brown R, Kabani K, Aklilu E, Ho PJ, Woodland N and Joshua D: Characterisation and relevance of CD138-negative plasma cells in plasma cell myeloma. Int J Lab Hematol 32: e190-e196, 2010.

6. Dimopoulos MA and Terpos E: Multiple myeloma. Ann Oncol 21 (Suppl 7): vii143-vii150, 2010.

7. Kyle RA: Multiple myeloma: How did it begin? Mayo Clin Proc 69: 680-683, 1994.

8. Kyle RA: Multiple myeloma: An odyssey of discovery. Br J Haematol 111: 1035-1044, 2000.

9. Durie BG, Harousseau JL, Miguel JS, Bladé J, Barlogie B, Anderson K, Gertz M, Dimopoulos M, Westin J, Sonneveld P, et al; International Myeloma Working Group: International uniform response criteria for multiple myeloma. Leukemia 20 : 1467-1473, 2006.

10. Rajkumar SV, Dimopoulos MA, Palumbo A, Blade J, Merlini G, Mateos MV, Kumar S, Hillengass J, Kastritis E, Richardson P, et al: International Myeloma Working Group updated criteria for the diagnosis of multiple myeloma. Lancet Oncol 15: e538-e548, 2014.

11. Martin NH: The immunoglobulins: A review. J Clin Pathol 22: 117-131, 1969.

12. Quach H, Ritchie D, Stewart AK, Neeson P, Harrison S, Smyth MJ and Prince HM: Mechanism of action of immunomodulatory drugs (IMiDS) in multiple myeloma. Leukemia 24 22-32, 2010.

13. Barlogie B, Shaughnessy J, Tricot G, Jacobson J, Zangari M, Anaissie E, Walker R and Crowley J: Treatment of multiple myeloma. Blood 103: 20-32, 2004.

14. Merchionne F, Perosa F and Dammacco F: New therapies in multiple myeloma. Clin Exp Med 7: 83-97, 2007.

15. Sonneveld P, Schoester M and de Leeuw K: Clinical modulation of multidrug resistance in multiple myeloma: Effect of cyclosporine on resistant tumor cells. J Clin Oncol 12: 1584-1591, 1994.

16. Sonneveld P, Durie BG, Lokhorst HM, Marie JP, Solbu G, Suciu S, Zittoun R, Löwenberg B and Nooter K; The Leukaemia Group of the EORTC and the HOVON: Modulation of multidrugresistant multiple myeloma by cyclosporin. Lancet 340: 255-259, 1992.
17. Gong J, Jaiswal R, Mathys JM, Combes V, Grau GE and Bebawy M: Microparticles and their emerging role in cancer multidrug resistance. Cancer Treat Rev 38: 226-234, 2012.

18. Biedler JL and Riehm H: Cellular resistance to actinomycin D in Chinese hamster cells in vitro: Cross-resistance, radioautographic, and cytogenetic studies. Cancer Res 30: 1174-1184, 1970.

19. Turesson I, Velez R, Kristinsson SY and Landgren O: Patterns of improved survival in patients with multiple myeloma in the twenty-first century: A population-based study. J Clin Oncol 28: 830-834, 2010.

20. Decaux O, Lodé L, Magrangeas F, Charbonnel C, Gouraud W, Jézéquel P, Attal M, Harousseau JL, Moreau P, Bataille R, et al; Intergroupe Francophone du Myélome: Prediction of survival in multiple myeloma based on gene expression profiles reveals cell cycle and chromosomal instability signatures in high-risk patients and hyperdiploid signatures in low-risk patients: A study of the Intergroupe Francophone du Myélome. J Clin Oncol 26: 4798-4805, 2008.

21. Garrison LP Jr, Wang ST, Huang H, Ba-Mancini A, Shi H, Chen K, Korves C, Dhawan R, Cakana A, van de Velde H, et al: The cost-effectiveness of initial treatment of multiple myeloma in the U.S. with bortezomib plus melphalan and prednisone versus thalidomide plus melphalan and prednisone or lenalidomide plus melphalan and prednisone with continuous lenalidomide maintenance treatment. Oncologist 18: 27-36, 2013.

22. Gaultney JG, Franken MG, Tan SS, Redekop WK, Huijgens PC, Sonneveld P and Uyl-de Groot CA: Real-world health care costs of relapsed/refractory multiple myeloma during the era of novel cancer agents. J Clin Pharm Ther 38: 41-47, 2013.

23. Goodwin JA, Coleman EA, Sullivan E, Easley R, McNatt PK, Chowdhury N and Stewart CB: Personal Financial Effects of Multiple Myeloma and Its Treatment. Cancer Nurs 36: 301-308, 2013.

24. Durie B, Binder G, Pashos C, Khan Z, Hussein M and Borrello I: Total cost comparison in relapsed/refractory multiple myeloma. J Med Econ 16: 614-622, 2013.

25 . Bergsagel D: The incidence and epidemiology of plasma cell neoplasms. Stem Cells 13 (Suppl 2): 1-9, 1995.

26. Chen-Kiang S: Cell-cycle control of plasma cell differentiation and tumorigenesis. Immunol Rev 194: 39-47, 2003.

27. Caraux A, Klein B, Paiva B, Bret C, Schmitz A, Fuhler GM, Bos NA, Johnsen HE, Orfao A and Perez-Andres M; Myeloma Stem Cell Network: Circulating human B and plasma cells. Age-associated changes in counts and detailed characterization of circulating normal CD138 and $\mathrm{CD} 138^{+}$plasma cells Haematologica 95: 1016-1020, 2010.

28. Alessio M, Roggero S, Funaro A, De Monte LB, Peruzzi L, Geuna $M$ and Malavasi F: CD38 molecule: Structural and biochemical analysis on human T lymphocytes, thymocytes, and plasma cells. J Immunol 145: 878-884, 1990.

29. Ruiz-Argüelles GJ and San Miguel JF: Cell surface markers in multiple myeloma. Mayo Clin Proc 69: 684-690, 1994.

30. Kara IO, Sahin B, Paydas S and Cetiner S: Flow cytometric evaluation of bone marrow plasma cells using CD19, CD45, CD56, CD38, and CD138 and correlation with bone marrow infiltration ratio in multiple myeloma patients. Saudi Med J 25: 1587-1592, 2004.

31. Rawstron AC: Immunophenotyping of plasma cells. Curr Protoc Cytom, 2006. Chapter 6: p. Unit6.23.

32. Bayer-Garner IB, Sanderson RD, Dhodapkar MV, Owens RB and Wilson CS: Syndecan-1 (CD138) immunoreactivity in bone marrow biopsies of multiple myeloma: Shed syndecan-1 accumulates in fibrotic regions. Mod Pathol 14: 1052-1058, 2001.

33. Tokoyoda K, Hauser AE, Nakayama T and Radbruch A: Organization of immunological memory by bone marrow stroma. Nat Rev Immunol 10: 193-200, 2010.

34. Moser K, Tokoyoda K, Radbruch A, MacLennan I and Manz RA: Stromal niches, plasma cell differentiation and survival. Curr Opin Immunol 18: 265-270, 2006.

35. Vande Broek I, Vanderkerken K, Van Camp B and Van Riet I: Extravasation and homing mechanisms in multiple myeloma. Clin Exp Metastasis 25: 325-334, 2008.

36. Alexander DD, Mink PJ, Adami HO, Cole P, Mandel JS, Oken MM and Trichopoulos D: Multiple myeloma: A review of the epidemiologic literature. Int J Cancer 120 (Suppl 12): 40-61, 2007.

37. Brigden ML: The search for meaning in monoclonal protein. Is it multiple myeloma or monoclonal gammopathy of undetermined significance? Postgrad Med 106: 135-142, quiz 185, 1999. 
38. Kyle RA, Therneau TM, Rajkumar SV, Offord JR, Larson DR, Plevak MF and Melton LJ III: A long-term study of prognosis in monoclonal gammopathy of undetermined significance. N Engl J Med 346: 564-569, 2002.

39. Fonseca R, Barlogie B, Bataille R, Bastard C, Bergsagel PL, Chesi M, Davies FE, Drach J, Greipp PR, Kirsch IR, et al: Genetics and cytogenetics of multiple myeloma: A workshop report. Cancer Res 64: 1546-1558, 2004.

40. Pilarski LM and Belch AR: Circulating monoclonal B cells expressing $\mathrm{P}$ glycoprotein may be a reservoir of multidrugresistant disease in multiple myeloma. Blood 83: 724-736, 1994.

41. Bergsagel PL, Kuehl WM, Zhan F, Sawyer J, Barlogie B and Shaughnessy J Jr: Cyclin D dysregulation: An early and unifying pathogenic event in multiple myeloma. Blood 106: 296-303, 2005.

42. Hundemer M, Klein U, Hose D, Raab MS, Cremer FW, Jauch A, Benner A, Heiss C, Moos M, Ho AD, et al: Lack of CD56 expression on myeloma cells is not a marker for poor prognosis in patients treated by high-dose chemotherapy and is associated with translocation $\mathrm{t}(11 ; 14)$. Bone Marrow Transplant 40 1033-1037, 2007

43. Chang H, Samiee S and Yi QL: Prognostic relevance of CD56 expression in multiple myeloma: A study including 107 cases treated with high-dose melphalan-based chemotherapy and autologous stem cell transplant. Leuk Lymphoma 47: 43-47, 2006.

44. Van Camp B, Durie BG, Spier C, De Waele M, Van Riet I, Vela E, Frutiger Y, Richter L and Grogan TM: Plasma cells in multiple myeloma express a natural killer cell-associated antigen: CD56 (NKH-1; Leu-19). Blood 76: 377-382, 1990.

45. Van Riet I and Van Camp B: The involvement of adhesion molecules in the biology of multiple myeloma. Leuk Lymphoma 9: 441-452, 1993.

46. Rawstron AC, Owen RG, Davies FE, Johnson RJ, Jones RA Richards SJ, Evans PA, Child JA, Smith GM, Jack AS, et al: Circulating plasma cells in multiple myeloma: Characterization and correlation with disease stage. Br J Haematol 97: 46-55, 1997.

47. O'Connell FP, Pinkus JL and Pinkus GS: CD138 (syndecan-1), a plasma cell marker immunohistochemical profile in hematopoietic and nonhematopoietic neoplasms. Am J Clin Pathol 121: 254-263, 2004

48. Matsui W, Huff CA, Wang Q, Malehorn MT, Barber J, Tanhehco Y, Smith BD, Civin CI and Jones RJ: Characterization of clonogenic multiple myeloma cells. Blood 103: 2332-2336, 2004.

49. Kyle RA and Rajkumar SV: Criteria for diagnosis, staging, risk stratification and response assessment of multiple myeloma. Leukemia 23: 3-9, 2009.

50. Palumbo A, Attal M and Roussel M: Shifts in the therapeutic paradigm for patients newly diagnosed with multiple myeloma: Maintenance therapy and overall survival. Clin Cancer Res 17: $1253-1263,2011$.

51. Lonial S and Kaufman JL: Non-secretory myeloma: a clinician's guide. Oncology (Williston Park) 27: 924-930, 2013.

52. Cavo M, Rajkumar SV, Palumbo A, Moreau P, Orlowski R, Bladé J, Sezer O, Ludwig H, Dimopoulos MA, Attal M, et al; International Myeloma Working Group: International Myeloma Working Group consensus approach to the treatment of multiple myeloma patients who are candidates for autologous stem cell transplantation. Blood 117: 6063-6073, 2011

53. Fernández de Larrea C, Delforge M, Davies F and Bladé J: Response evaluation and monitoring of multiple myeloma. Expert Rev Hematol 7: 33-42, 2014.

54. Greipp PR, San Miguel J, Durie BG, Crowley JJ, Barlogie B, Bladé J, Boccadoro M, Child JA, Avet-Loiseau H, Kyle RA, et al: International staging system for multiple myeloma. J Clin Oncol 23: 3412-3420, 2005.

55. Hari PN, Zhang MJ, Roy V, Pérez WS, Bashey A, To LB, Elfenbein G, Freytes CO, Gale RP, Gibson J, et al: Is the International Staging System superior to the Durie-Salmon staging system? A comparison in multiple myeloma patients undergoing autologous transplant. Leukemia 23: 1528-1534, 2009.

56. Durie BG and Salmon SE: A clinical staging system for multiple myeloma. Correlation of measured myeloma cell mass with presenting clinical features, response to treatment, and survival. Cancer 36: 842-854, 1975.

57. Salmon SE and Durie BG: Cellular kinetics in multiple myeloma A new approach to staging and treatment. Arch Intern Med 135 $131-138,1975$.
58. Palumbo A, Bringhen S, Falco P, Cavallo F, Ambrosini MT, Avonto I, Gay F, Caravita T, Bruno B and Boccadoro M: Time to first disease progression, but not beta2-microglobulin, predicts outcome in myeloma patients who receive thalidomide as salvage therapy. Cancer 110: 824-829, 2007.

59. Hungria VT, Maiolino A, Martinez G, Colleoni GW, Coelho EO, Rocha L, Nunes R, Bittencourt R, Oliveira LC, Faria RM, et al; International Myeloma Working Group Latin America: Confirmation of the utility of the International Staging System and identification of a unique pattern of disease in Brazilian patients with multiple myeloma. Haematologica 93: 791-792, 2008.

60. Kuehl WM and Bergsagel PL: Multiple myeloma: Evolving genetic events and host interactions. Nat Rev Cancer 2: 175-187, 2002.

61. Sawyer JR: The prognostic significance of cytogenetics and molecular profiling in multiple myeloma. Cancer Genet 204: 3-12, 2011.

62. Stewart AK and Fonseca R: Prognostic and therapeutic significance of myeloma genetics and gene expression profiling. J Clin Oncol 23: 6339-6344, 2005

63. Liebisch P and Döhner H: Cytogenetics and molecular cytogenetics in multiple myeloma. Eur J Cancer 42: 1520-1529, 2006.

64. Kuehl WM and Bergsagel PL: Early genetic events provide the basis for a clinical classification of multiple myeloma. Hematology Am Soc Hematol Educ Program 2005: 346-352, 2005.

65. Pichiorri F, De Luca L and Aqeilan RI: MicroRNAs: New players in multiple myeloma. Front Genet 2: 22, 2011.

66. Bartel DP: MicroRNAs: Genomics, biogenesis, mechanism, and function. Cell 116: 281-297, 2004.

67. Petrocca F, Visone R, Onelli MR, Shah MH, Nicoloso MS, de Martino I, Iliopoulos D, Pilozzi E, Liu CG, Negrini M, et al: E2F1-regulated microRNAs impair TGFbeta-dependent cellcycle arrest and apoptosis in gastric cancer. Cancer Cell 13: 272-286, 2008

68. Roccaro AM, Sacco A, Thompson B, Leleu X, Azab AK, Azab F, Runnels J, Jia X, Ngo HT, Melhem MR, et al: MicroRNAs $15 \mathrm{a}$ and 16 regulate tumor proliferation in multiple myeloma. Blood 113: 6669-6680, 2009.

69. Cao J,Hong CH, Rosen L, Vescio RA, Smulson M,Lichtenstein AK and Berenson JR: Deletion of genetic material from a poly(ADPribose) polymerase-like gene on chromosome 13 occurs frequently in patients with monoclonal gammopathies. Cancer Epidemiol Biomarkers Prev 4: 759-763, 1995.

70. Lopes da Silva R, Monteiro A and Veiga J: Non-secretory multiple myeloma relapsing as extramedullary liver plasmacytomas. J Gastrointestin Liver Dis 20: 81-83, 2011.

71. Mehta J and Singhal S: Hyperviscosity syndrome in plasma cell dyscrasias. Semin Thromb Hemost 29: 467-471, 2003.

72. Brown JH and Doherty CC: Renal replacement therapy in multiple myeloma and systemic amyloidosis. Postgrad Med J 69: 672-678, 1993.

73. Goldschmidt H, Lannert H, Bommer J and Ho AD: Multiple myeloma and renal failure. Nephrol Dial Transplant 15: 301-304, 2000 .

74. Yaccoby S: The phenotypic plasticity of myeloma plasma cells as expressed by dedifferentiation into an immature, resilient, and apoptosis-resistant phenotype. Clin Cancer Res 11: 7599-7606, 2005.

75. Yaccoby S: Advances in the understanding of myeloma bone disease and tumour growth. Br J Haematol 149: 311-321, 2010.

76. Brown R, Kabani K, Favaloro J, Yang S, Ho PJ, Gibson J, Fromm P, Suen H, Woodland N, Nassif N, Hart D and Joshua D: CD86 ${ }^{+}$ or HLA-G ${ }^{+}$myeloma cells are associated with poor prognosis and once acquired by trogocytosis create novel Tregacq cells. Blood 120: 2055-2063, 2012.

77. Osborne DG and Wetzel SA: Trogocytosis results in sustained intracellular signaling in CD4(+) T cells. J Immunol 189: 4728-4739, 2012.

78. Cook G: Has the $\mathrm{T}$ cell bitten off more than it can chew? Blood 120: 1966-1967, 2012.

79. Nau KC and Lewis WD: Multiple myeloma: Diagnosis and treatment. Am Fam Physician 78: 853-859, 2008.

80. Tanaka Y1, Abe M, Hiasa M, Oda A, Amou H, Nakano A, Takeuchi K, Kitazoe K, Kido S, Inoue D, et al: Myeloma cellosteoclast interaction enhances angiogenesis together with bone resorption: a role for vascular endothelial cell growth factor and osteopontin. Clin Cancer Res 13: 816-823, 2007.

81. Abe M, Hiura K, Wilde J, Shioyasono A, Moriyama K, Hashimoto T, Kido S, Oshima T, Shibata H, Ozaki S, et al: Osteoclasts enhance myeloma cell growth and survival via cell-cell contact: A vicious cycle between bone destruction and myeloma expansion. Blood 104: 2484-2491, 2004. 
82. Hideshima T, Chauhan D, Schlossman R, Richardson P and Anderson KC: The role of tumor necrosis factor alpha in the pathophysiology of human multiple myeloma: Therapeutic applications. Oncogene 20: 4519-4527, 2001.

83. Ge NL and Rudikoff S: Insulin-like growth factor I is a dual effector of multiple myeloma cell growth. Blood 96: 2856-2861, 2000

84. Hideshima T and Anderson KC: Molecular mechanisms of novel therapeutic approaches for multiple myeloma. Nat Rev Cancer 2: 927-937, 2002

85. Brenne AT, Ro TB, Waage A, Sundan A, Borset M and Hjorth-Hansen H: Interleukin-21 is a growth and survival factor for human myeloma cells. Blood 99: 3756-3762, 2002.

86. Podar K, Tai YT, Davies FE, Lentzsch S, Sattler M, Hideshima T, Lin BK, Gupta D, Shima Y, Chauhan D, et al: Vascular endothelia growth factor triggers signaling cascades mediating multiple myeloma cell growth and migration. Blood 98: 428-435, 2001.

87. Hideshima T, Chauhan D, Hayashi T, Podar K, Akiyama M, Gupta D, Richardson P, Munshi N and Anderson KC: The biological sequelae of stromal cell-derived factor-1alpha in multiple myeloma. Mol Cancer Ther 1: 539-544, 2002.

88. Sanz-Rodríguez F and Teixidó J: VLA-4-dependent myeloma cell adhesion. Leuk Lymphoma 41: 239-245, 2001.

89. Michigami T, Shimizu N, Williams PJ, Niewolna M, Dallas SL, Mundy GR and Yoneda T: Cell-cell contact between marrow stromal cells and myeloma cells via VCAM-1 and alpha(4) beta(1)-integrin enhances production of osteoclast-stimulating activity. Blood 96: 1953-1960, 2000.

90. Abdi J, Chen G and Chang H: Drug resistance in multiple myeloma: Latest findings and new concepts on molecular mechanisms. Oncotarget 4: 2186-2207, 2013.

91. Ogata A, Chauhan D, Teoh G, Treon SP, Urashima M, Schlossman RL and Anderson KC: IL-6 triggers cell growth via the Ras-dependent mitogen-activated protein kinase cascade. J Immunol 159: 2212-2221, 1997.

92. Hideshima T, Nakamura N, Chauhan D and Anderson KC: Biologic sequelae of interleukin-6 induced PI3-K/Akt signaling in multiple myeloma. Oncogene 20: 5991-6000, 2001.

93. Burger R, Le Gouill S, Tai YT, Shringarpure R, Tassone P, Neri P, Podar K, Catley L, Hideshima T, Chauhan D, et al: Janus kinase inhibitor INCB20 has antiproliferative and apoptotic effects on human myeloma cells in vitro and in vivo. Mol Cancer Ther 8: 26-35, 2009.

94. Kumar A, Galeb S and Djulbegovic B: Treatment of patients with multiple myeloma: An overview of systematic reviews. Acta Haematol 125: 8-22, 2011.

95. Andhavarapu S and Roy V: Immunomodulatory drugs in multiple myeloma. Expert Rev Hematol 6: 69-82, 2013.

96. Knight R: IMiDs: A novel class of immunomodulators. Semin Oncol 32 (Suppl 5): S24-S30, 2005

97.Ludwig H, Adam Z, Tóthová E, Hajek R, Labar B, Egyed M, Spicka I, Gisslinger H, Drach J, Kuhn I, et al: Thalidomide maintenance treatment increases progression-free but not overall survival in elderly patients with myeloma. Haematologica 95 $1548-1554,2010$.

98.Palumbo A, Miguel JS, Sonneveld P, Moreau P, Drach J, Morgan $\mathrm{G}$ and Einsele H: Lenalidomide: A new therapy for multiple myeloma. Cancer Treat Rev 34: 283-291, 2008.

99.Richardson $\mathrm{P}$ and Anderson $\mathrm{K}$ : Thalidomide and dexamethasone: A new standard of care for initial therapy in multiple myeloma. J Clin Oncol 24: 334-336, 2006.

100. Rajkumar SV, Dispenzieri A, Fonseca R, Lacy MQ, Geyer S, Lust JA, Kyle RA, Greipp PR, Gertz MA and Witzig TE: Thalidomide for previously untreated indolent or smoldering multiple myeloma. Leukemia 15: 1274-1276, 2001.

101.Prince HM, Schenkel B and Mileshkin L: An analysis of clinical trials assessing the efficacy and safety of single-agent thalidomide in patients with relapsed or refractory multiple myeloma. Leuk Lymphoma 48: 46-55, 2007.

102. Cavo M, Zamagni E, Tosi P, Cellini C, Cangini D, Tacchetti P, Testoni N, Tonelli M, de Vivo A, Palareti G, et al: First-line therapy with thalidomide and dexamethasone in preparation for autologous stem cell transplantation for multiple myeloma. Haematologica 89: 826-831, 2004.

103. Rajkumar SV, Blood E, Vesole D, Fonseca R and Greipp PR; Eastern Cooperative Oncology Group: Phase III clinical trial of thalidomide plus dexamethasone compared with dexamethasone alone in newly diagnosed multiple myeloma: A clinical trial coordinated by the Eastern Cooperative Oncology Group. J Clin Oncol 24: 431-436, 2006.
104. Wu P, Davies FE, Horton C, Jenner MW, Krishnan B, Alvares CL, Saso R, McCormack R, Dines S, Treleaven JG, et al: The combination of cyclophosphomide, thalidomide and dexamethasone is an effective alternative to cyclophosphamide - vincristine - doxorubicin - methylprednisolone as induction chemotherapy prior to autologous transplantation for multiple myeloma: A case-matched analysis. Leuk Lymphoma 47: 2335-2338, 2006.

105.Dimopoulos MA, Hamilos G, Zomas A, Gika D, Efstathiou E, Grigoraki V, Poziopoulos C, Xilouri I, Zorzou MP, Anagnostopoulos N, et al: Pulsed cyclophosphamide, thalidomide and dexamethasone: An oral regimen for previously treated patients with multiple myeloma. Hematol J 5: 112-117, 2004.

106. García-Sanz R, González-Fraile MI, Sierra M, López C, González M and San Miguel JF: The combination of thalidomide, cyclophosphamide and dexamethasone (ThaCyDex) is feasible and can be an option for relapsed/refractory multiple myeloma. Hematol J 3: 43-48, 2002.

107. Morgan GJ, Jackson GH, Davies FE, Drayson MT, Owen RG, Gregory WM, Cohen DC, Szubert AJ, Bell SE, Ross F and Child JA: Maintenance thalidomide may improve progression free but not overall survival; results from the Myeloma IX Maintenance Randomisation. Blood (ASH Annual Meeting Abstracts) 112: 656, 2008

108. Morgan GJ, Gregory WM, Davies FE, Bell SE, Szubert AJ, Brown JM, Coy NN, Cook G, Russell NH, Rudin C, Roddie H, Drayson MT, Owen RG, Ross FM, Jackson GH and Child JA; National Cancer Research Institute Haematological Oncology Clinical Studies Group: The role of maintenance thalidomide therapy in multiple myeloma: MRC myeloma IX results and meta-analysis. Blood 119: 7-15, 2012.

109. Oakervee HE, Popat R, Curry N, Smith P, Morris C, Drake M, Agrawal S, Stec J, Schenkein D, Esseltine DL, et al: PAD combination therapy (PS-341/bortezomib, doxorubicin and dexamethasone) for previously untreated patients with multiple myeloma. Br J Haematol 129: 755-762, 2005

110. Popat R, Oakervee HE, Hallam S, Curry N, Odeh L, Foot N, Esseltine DL, Drake M, Morris C and Cavenagh JD: Bortezomib, doxorubicin and dexamethasone (PAD) front-line treatment of multiple myeloma: Updated results after long-term follow-up. $\mathrm{Br}$ J Haematol 141: 512-516, 2008.

111. Mateos MV, Hernández JM, Hernández MT, Gutiérrez NC, Palomera L, Fuertes M, Díaz-Mediavilla J, Lahuerta JJ, de la Rubia J, Terol MJ, et al: Bortezomib plus melphalan and prednisone in elderly untreated patients with multiple myeloma: Results of a multicenter phase 1/2 study. Blood 108: 2165-2172, 2006.

112. Rajkumar SV, Hayman SR, Lacy MQ, Dispenzieri A, Geyer SM, Kabat B, Zeldenrust SR, Kumar S, Greipp PR, Fonseca R, et al: Combination therapy with lenalidomide plus dexamethasone (Rev/Dex) for newly diagnosed myeloma. Blood 106: 4050-4053, 2005.

113. Bladé J, Samson D, Reece D, Apperley J, Björkstrand B, Gahrton G, Gertz M, Giralt S, Jagannath S and Vesole D Myeloma Subcommittee of the EBMT. European Group for Blood and Marrow Transplant: Criteria for evaluating disease response and progression in patients with multiple myeloma treated by high-dose therapy and haemopoietic stem cell transplantation. Br J Haematol 102: 1115-1123, 1998

114. Alexanian R, Delasalle K, Wang M, Thomas S and Weber D: Curability of multiple myeloma. Bone Marrow Res 2012: $916479,2012$.

115. Boccadoro M, Gavarotti P, Fossati G, Pileri A, Marmont F, Neretto G, Gallamini A, Volta C, Tribalto M, Testa MG, et al Low plasma cell $3(\mathrm{H})$ thymidine incorporation in monoclonal gammopathy of undetermined significance (MGUS), smouldering myeloma and remission phase myeloma: A reliable indicator of patients not requiring therapy. Br J Haematol 58: 689-696, 1984.

116. Brown RD, Joshua DE, Nelson M, Gibson J, Dunn J and MacLennan IC: Serum thymidine kinase as a prognostic indicator for patients with multiple myeloma: results from the MRC (UK) V Trial. Br J Haematol 84: 238-241, 1993

117. Lust JA, Lacy MQ, Zeldenrust SR, Dispenzieri A, Gertz MA Witzig TE, Kumar S, Hayman SR, Russell SJ, Buadi FK, et al: Induction of a chronic disease state in patients with smoldering or indolent multiple myeloma by targeting interleukin 1 \{beta\}induced interleukin 6 production and the myeloma proliferative component. Mayo Clin Proc 84: 114-122, 2009. 
118. Joshua DE, Gibson J and Brown RD: Mechanisms of the escape phase of myeloma. Blood Rev 8: 13-20, 1994.

119. Lonial S, Mitsiades CS and Richardson PG: Treatment options for relapsed and refractory multiple myeloma. Clin Cancer Res 17: 1264-1277, 2011.

120. Alexanian R, Barlogie B and Dixon D: High-dose glucocorticoid treatment of resistant myeloma. Ann Intern Med 105: 8-11, 1986

121. McPhedran P, Heath CW Jr and Garcia J: Multiple myeloma incidence in metropolitan Atlanta, Georgia: Racial and seasonal variations. Blood 39: 866-873, 1972.

122. Clark DW and MacMahon B: The incidence of multiple myeloma. J Chronic Dis 4: 508-515, 1956.

123. Greenberg AJ, Vachon CM and Rajkumar SV: Disparities in the prevalence, pathogenesis and progression of monoclonal gammopathy of undetermined significance and multiple myeloma between blacks and whites. Leukemia 26: 609-614, 2012.

124. Matsui W, Wang Q, Barber JP, Brennan S, Smith BD, Borrello I, McNiece I, Lin L, Ambinder RF, Peacock C, et al: Clonogenic multiple myeloma progenitors, stem cell properties, and drug resistance. Cancer Res 68: 190-197, 2008.

125. Du J, Liu S, He J, Liu X, Qu Y, Yan W, Fan J, Li R, Xi H, Fu W, et al: MicroRNA-451 regulates stemness of side population cells via $\mathrm{PI} 3 \mathrm{~K} / \mathrm{Akt} / \mathrm{mTOR}$ signaling pathway in multiple myeloma. Oncotarget 6: 14993-15007, 2015

126. Agarwal JR and Matsui W: Multiple myeloma: A paradigm for translation of the cancer stem cell hypothesis. Anticancer Agents Med Chem 10: 116-120, 2010.

127. Pilarski LM, Mant MJ and Belch AR: Drug resistance in multiple myeloma: Novel therapeutic targets within the malignant clone Leuk Lymphoma 32: 199-210, 1999.

128. Koskela K, Pelliniemi TT and Remes K: VAD regimen in the treatment of resistant multiple myeloma: Slow or fast infusion? Leuk Lymphoma 10: 347-351, 1993.

129. Harris AL and Hochhauser D: Mechanisms of multidrug resistance in cancer treatment. Acta Oncol 31: 205-213, 1992.

130. Sonneveld P, Lokhorst HM and Vossebeld P: Drug resistance in multiple myeloma. Semin Hematol 34 (Suppl 5): 34-39, 1997.

131. Tucci M, Quatraro C, Dammacco F and Silvestris F: Role of active drug transporters in refractory multiple myeloma. Curr Top Med Chem 9: 218-224, 2009.

132. Wang JC: DNA topoisomerases. Annu Rev Biochem 65: 635-692, 1996.

133. Liu LF: DNA topoisomerase poisons as antitumor drugs. Annu Rev Biochem 58: 351-375, 1989.

134. Oloumi A, MacPhail SH, Johnston PJ, Banáth JP and Olive PL: Changes in subcellular distribution of topoisomerase IIalpha correlate with etoposide resistance in multicell spheroids and xenograft tumors. Cancer Res 60: 5747-5753, 2000.

135.Turner JG, Marchion DC, Dawson JL, Emmons MF, Hazlehurst LA, Washausen P and Sullivan DM: Human multiple myeloma cells are sensitized to topoisomerase II inhibitors by CRM1 inhibition. Cancer Res 69: 6899-6905, 2009.

136. Campling BG, Baer K, Baker HM, Lam YM and Cole SP: Do glutathione and related enzymes play a role in drug resistance in small cell lung cancer cell lines? Br J Cancer 68: 327-335, 1993

137. Garel MC, Domenget C, Caburi-Martin J, Prehu C, Galacteros F and Beuzard Y: Covalent binding of glutathione to hemoglobin I. Inhibition of hemoglobin S polymerization. J Biol Chem 261: 14704-14709, 1986

138. Petrini M, Di Simone D, Favati A, Mattii L, Valentini P and Grassi B: GST-pi and P-170 co-expression in multiple myeloma. Br J Haematol 90: 393-397, 1995.

139. Manier S, Sacco A, Leleu X, Ghobrial IM and Roccaro AM: Bone marrow microenvironment in multiple myeloma progression. J Biomed Biotechnol 2012: 157496, 2012.

140. Meads MB, Gatenby RA and Dalton WS: Environmentmediated drug resistance: A major contributor to minimal residual disease. Nat Rev Cancer 9: 665-674, 2009.

141. Shain KH and Dalton WS: Cell adhesion is a key determinant in de novo multidrug resistance (MDR): New targets for the prevention of acquired MDR. Mol Cancer Ther 1: 69-78, 2001.

142. Damiano JS, Cress AE, Hazlehurst LA, Shtil AA and Dalton WS: Cell adhesion mediated drug resistance (CAM-DR): Role of integrins and resistance to apoptosis in human myeloma cell lines. Blood 93: 1658-1667, 1999.

143. Mitsiades CS, Treon SP, Mitsiades N, Shima Y, Richardson P, Schlossman R, Hideshima T and Anderson KC: TRAIL/Apo2L ligand selectively induces apoptosis and overcomes drug resistance in multiple myeloma: Therapeutic applications. Blood 98: 795-804, 2001.
144. Mitsiades N, Mitsiades CS, Poulaki V, Chauhan D, Richardson PG, Hideshima T, Munshi NC, Treon SP and Anderson KC: Apoptotic signaling induced by immunomodulatory thalidomide analogs in human multiple myeloma cells: Therapeutic implications. Blood 99: 4525-4530, 2002.

145. Chauhan D, Pandey P, Hideshima T, Treon S, Raje N, Davies FE, Shima Y, Tai YT, Rosen S, Avraham S, et al: SHP2 mediates the protective effect of interleukin-6 against dexamethasoneinduced apoptosis in multiple myeloma cells. J Biol Chem 275 27845-27850, 2000

146. Hideshima T, Richardson P, Chauhan D, Palombella VJ, Elliott PJ, Adams J and Anderson KC: The proteasome inhibitor PS-341 inhibits growth, induces apoptosis, and overcomes drug resistance in human multiple myeloma cells. Cancer Res 61: 3071-3076, 2001.

147. Dalton WS and Jove R: Drug resistance in multiple myeloma: Approaches to circumvention. Semin Oncol 26 (Suppl 13) 23-27, 1999.

148. Mitsiades CS, Mitsiades N, Poulaki V, Schlossman R, Akiyama M, Chauhan D, Hideshima T, Treon SP, Munshi NC, Richardson PG, et al: Activation of NF-kappaB and upregulation of intracellular anti-apoptotic proteins via the IGF-1/Akt signaling in human multiple myeloma cells: Therapeutic implications. Oncogene 21: 5673-5683, 2002.

149. Hideshima T, Chauhan D, Richardson P, Mitsiades C, Mitsiades N, Hayashi T, Munshi N, Dang L, Castro A, Palombella V, et al: NF-kappa B as a therapeutic target in multiple myeloma. J Biol Chem 277: 16639-16647, 2002.

150. Nefedova Y, Landowski TH and Dalton WS: Bone marrow stromal-derived soluble factors and direct cell contact contribute to de novo drug resistance of myeloma cells by distinct mechanisms. Leukemia 17: 1175-1182, 2003.

151. Kühne A, Tzvetkov MV, Hagos Y, Lage H, Burckhardt G and Brockmöller J: Influx and efflux transport as determinants of melphalan cytotoxicity: Resistance to melphalan in MDR1 overexpressing tumor cell lines. Biochem Pharmacol 78: 45-53, 2009.

152. Doyle L and Ross DD: Multidrug resistance mediated by the breast cancer resistance protein BCRP (ABCG2). Oncogene 22: 7340-7358, 2003.

153. Raaijmakers HG, Izquierdo MA, Lokhorst HM, de Leeuw C, Belien JA, Bloem AC, Dekker AW, Scheper RJ and Sonneveld P. Lung-resistance-related protein expression is a negative predictive factor for response to conventional low but not to intensified dose alkylating chemotherapy in multiple myeloma. Blood 91: 1029-1036, 1998 .

154. Hofmeister CC, Yang X, Pichiorri F, Chen P, Rozewski DM, Johnson AJ, Lee S, Liu Z, Garr CL, Hade EM, et al: Phase I trial of lenalidomide and CCI-779 in patients with relapsed multiple myeloma: Evidence for lenalidomide-CCI-779 interaction via P-glycoprotein. J Clin Oncol 29: 3427-3434, 2011.

155. Tong Z, Yerramilli U, Surapaneni S and Kumar G: The interactions of lenalidomide with human uptake and efflux transporters and UDP-glucuronosyltransferase 1A1: Lack of potential for drug-drug interactions. Cancer Chemother Pharmacol 73: 869-874,2014.

156.Jiang Y: Pharmacokinetic and pharmacodynamic studies of lenalidomide and pomalidomide. (Electronic Thesis or Dissertation). Retrieved from https://etd.ohiolink.edu/.

157. O'Connor R, Ooi MG, Meiller J, Jakubikova J, Klippel S, Delmore J, Richardson P, Anderson K, Clynes M, Mitsiades CS, et al: The interaction of bortezomib with multidrug transporters: Implications for therapeutic applications in advanced multiple myeloma and other neoplasias. Cancer Chemother Pharmacol 71: 1357-1368, 2013

158. Nakamura T, Tanaka K, Matsunobu T, Okada T, Nakatani $F$ Sakimura R, Hanada M and Iwamoto Y: The mechanism of cross-resistance to proteasome inhibitor bortezomib and overcoming resistance in Ewing's family tumor cells. Int J Oncol 31: 803-811, 2007

159. Zimmermann C, Gutmann $\mathrm{H}$ and Drewe J: Thalidomide does not interact with P-glycoprotein. Cancer Chemother Pharmacol 57: 599-606, 2006.

160. Dilger K, AlbererM, Busch A, Enninger A,Behrens R, Koletzko S, Stern M, Beckmann C and Gleiter $\mathrm{CH}$ : Pharmacokinetics and pharmacodynamic action of budesonide in children with Crohn's disease. Aliment Pharmacol Ther 23: 387-396, 2006.

161. Karssen AM, Meijer OC, van der Sandt IC, De Boer AG, De Lange EC and De Kloet ER: The role of the efflux transporter P-glycoprotein in brain penetration of prednisolone. J Endocrinol 175: 251-260, 2002. 
162. Shapiro AB and Ling V: Positively cooperative sites for drug transport by P-glycoprotein with distinct drug specificities. Eur J Biochem 250: 130-137, 1997.

163. Cole SP and Deeley RG: Transport of glutathione and glutathione conjugates by MRP1. Trends Pharmacol Sci 27: 438-446, 2006.

164. Robey RW, Shukla S, Finley EM, Oldham RK, Barnett D, Ambudkar SV, Fojo $\mathrm{T}$ and Bates SE: Inhibition of P-glycoprotein (ABCB1)- and multidrug resistance-associated protein 1 (ABCC1)-mediated transport by the orally administered inhibitor, CBT-1((R)). Biochem Pharmacol 75: 1302-1312, 2008

165. Kitazono M, Sumizawa T, Takebayashi Y, Chen ZS, Furukawa T, Nagayama S, Tani A, Takao S, Aikou T and Akiyama S: Multidrug resistance and the lung resistance-related protein in human colon carcinoma SW-620 cells. J Natl Cancer Inst 91: 1647-1653, 1999.

166. Kang W and Weiss M: Digoxin uptake, receptor heterogeneity, and inotropic response in the isolated rat heart: A comprehensive kinetic model. J Pharmacol Exp Ther 302: 577-583, 2002.

167. Abbaszadegan MR, Futscher BW, Klimecki WT, List A and Dalton WS: Analysis of multidrug resistance-associated protein (MRP) messenger RNA in normal and malignant hematopoietic cells. Cancer Res 54: 4676-4679, 1994.

168. Duhem C, Ries F and Dicato M: What does multidrug resistance (MDR) expression mean in the clinic? Oncologist 1: $151-158,1996$.

169.Pilarski LM and Belch AR: Intrinsic expression of the multidrug transporter, P-glycoprotein 170, in multiple myeloma: Implications for treatment. Leuk Lymphoma 17: 367-374, 1995.

170. Nuessler V, Gieseler F, Gullis E, Pelka-Fleischer R, Stötzer O, Zwierzina $\mathrm{H}$ and Wilmanns W: Functional P-gp expression in multiple myeloma patients at primary diagnosis and relapse or progressive disease. Leukemia 11 (Suppl 5): S10-S14, 1997.

171.Drain S, Flannely L, Drake MB, Kettle P, Orr N, Bjourson AJ, Catherwood MA and Alexander HD: Multidrug resistance gene expression and ABCB1 SNPs in plasma cell myeloma. Leuk Res 35: 1457-1463, 2011.

172. Li YH, Wang YH, Li Y and Yang L: MDR1 gene polymorphisms and clinical relevance. Yi Chuan Xue Bao 33: 93-104, 2006.

173. Drain S, Catherwood MA, Orr N, Galligan L, Rea IM, Hodkinson C,Drake MB, Kettle PJ,Morris TC and Alexander HD: ABCB1 (MDR1) rs1045642 is associated with increased overall survival in plasma cell myeloma. Leuk Lymphoma 50: 566-570, 2009.

174.Buda G, Maggini V, Galimberti S, Martino A, Giuliani N, Morabito F, Genestreti G, Iacopino P, Rizzoli V, Barale R, et al: MDR1 polymorphism influences the outcome of multiple myeloma patients. Br J Haematol 137: 454-456, 2007.

175. Barrand MA, Bagrij T and Neo SY: Multidrug resistance-associated protein: A protein distinct from P-glycoprotein involved in cytotoxic drug expulsion. Gen Pharmacol 28: 639-645, 1997.

176. Davey RA, Longhurst TJ, Davey MW, Belov L, Harvie RM, Hancox D and Wheeler H: Drug resistance mechanisms and MRP expression in response to epirubicin treatment in a human leukaemia cell line. Leuk Res 19: 275-282, 1995.

177. Versantvoort CH, Broxterman HJ, Bagrij T, Scheper RJ and Twentyman PR: Regulation by glutathione of drug transport in multidrug-resistant human lung tumour cell lines overexpressing multidrug resistance-associated protein. Br J Cancer 72: 82-89, 1995.

178. Buda G, Ricci D, Huang CC, Favis R, Cohen N, Zhuang SH, Harousseau JL, Sonneveld P, Bladé J and Orlowski RZ: Polymorphisms in the multiple drug resistance protein 1 and in P-glycoprotein 1 are associated with time to event outcomes in patients with advanced multiple myeloma treated with bortezomib and pegylated liposomal doxorubicin. Ann Hematol 89: $1133-1140,2010$.

179. Grant CE, Valdimarsson G, Hipfner DR, Almquist KC, Cole SP and Deeley RG: Overexpression of multidrug resistance-associated protein (MRP) increases resistance to natural product drugs. Cancer Res 54: 357-361, 1994.

180.Lehne G: P-glycoprotein as a drug target in the treatment of multidrug resistant cancer. Curr Drug Targets 1: 85-99, 2000

181. Bart J, Hollema H, Groen HJ, de Vries EG, Hendrikse NH, Sleijfer DT, Wegman TD, Vaalburg W and van der Graaf WT: The distribution of drug-efflux pumps, P-gp, BCRP, MRP1 and MRP2, in the normal blood-testis barrier and in primary testicular tumours. Eur J Cancer 40: 2064-2070, 2004.

182. Cooray HC, Blackmore CG, Maskell L and Barrand MA: Localisation of breast cancer resistance protein in microvessel endothelium of human brain. Neuroreport 13: 2059-2063, 2002.
183. Xu J, Liu Y, Yang Y, Bates S and Zhang JT: Characterization of oligomeric human half-ABC transporter ATP-binding cassette G2. J Biol Chem 279: 19781-19789, 2004.

184. Raaijmakers MH, de Grouw EP, Heuver LH, van der Reijden BA, Jansen JH, Scheffer G, Scheper RJ, de Witte TJ and Raymakers RA: Impaired breast cancer resistance protein mediated drug transport in plasma cells in multiple myeloma. Leuk Res 29: 1455-1458, 2005.

185. Doyle LA, Yang W, Abruzzo LV, Krogmann T, Gao Y, Rishi AK and Ross DD: A multidrug resistance transporter from human MCF-7 breast cancer cells. Proc Natl Acad Sci USA 95: 15665-15670, 1998.

186. Jakubikova J, Adamia S, Kost-Alimova M, Klippel S, Cervi D, Daley JF, Cholujova D, Kong SY, Leiba M, Blotta S, et al: Lenalidomide targets clonogenic side population in multiple myeloma: Pathophysiologic and clinical implications. Blood 117: 4409-4419, 2011.

187. Turner JG, Gump JL, Zhang C, Cook JM, Marchion D, Hazlehurst L, Munster P, Schell MJ, Dalton WS and Sullivan DM: ABCG2 expression, function, and promoter methylation in human multiple myeloma. Blood 108: 3881-3889, 2006.

188. Tamura A, Wakabayashi K, Onishi Y, Takeda M, Ikegami Y, Sawada S, Tsuji M, Matsuda Y and Ishikawa T: Re-evaluation and functional classification of non-synonymous single nucleotide polymorphisms of the human ATP-binding cassette transporter ABCG2. Cancer Sci 98: 231-239, 2007.

189. Izquierdo MA, Scheffer GL, Flens MJ, Shoemaker RH, Rome LH and Scheper RJ: Relationship of LRP-human major vault protein to in vitro and clinical resistance to anticancer drugs. Cytotechnology 19: 191-197, 1996.

190. Feller N, Kuiper CM, Lankelma J, Ruhdal JK, Scheper RJ, Pinedo HM and Broxterman HJ: Functional detection of MDR1/P170 and MRP/P190-mediated multidrug resistance in tumour cells by flow cytometry. Br J Cancer 72: 543-549, 1995.

191. Sherry ST, Ward MH, Kholodov M, Baker J, Phan L, Smigielski EM and Sirotkin K: dbSNP: The NCBI database of genetic variation. Nucleic Acids Res 29: 308-311, 2001.

192. Henríquez-Hernández LA, Moreno M, Rey A, Lloret M and Lara PC: MVP expression in the prediction of clinical outcome of locally advanced oral squamous cell carcinoma patients treated with radiotherapy. Radiat Oncol 7: 1-6, 2012.

193. Litviakov NV, Cherdyntseva NV, Tsyganov MM, Denisov EV, Garbukov EY, Merzliakova MK, Volkomorov VV, Vtorushin SV, Zavyalova MV, Slonimskaya EM, et al: Changing the expression vector of multidrug resistance genes is related to neoadjuvant chemotherapy response. Cancer Chemother Pharmacol 71: 153-163, 2013.

194. van den Heuvel-Eibrink MM, Sonneveld P and Pieters R: The prognostic significance of membrane transport-associated multidrug resistance (MDR) proteins in leukemia. Int J Clin Pharmacol Ther 38: 94-110, 2000.

195.Herlevsen M, Oxford G, Owens CR, Conaway M and Theodorescu D: Depletion of major vault protein increases doxorubicin sensitivity and nuclear accumulation and disrupts its sequestration in lysosomes. Mol Cancer Ther 6: 1804-1813, 2007.

196. Sikic BI, Fisher GA, Lum BL, Halsey J, Beketic-Oreskovic L and Chen G: Modulation and prevention of multidrug resistance by inhibitors of P-glycoprotein. Cancer Chemother Pharmacol 40 (Suppl 1): S13-S19, 1997.

197. Sikic BI: Pharmacologic approaches to reversing multidrug resistance. Semin Hematol 34 (Suppl 5): 40-47, 1997.

198. Yang HH, Ma MH, Vescio RA and Berenson JR: Overcoming drug resistance in multiple myeloma: The emergence of therapeutic approaches to induce apoptosis. J Clin Oncol 21: 4239-4247, 2003

199. Fisher GA, Lum BL, Hausdorff J and Sikic BI: Pharmacological considerations in the modulation of multidrug resistance. Eur $\mathbf{J}$ Cancer 32A: 1082-1088, 1996.

200. Dalton W and Lehnert M: Dexverapamil: A clinical approach to circumvention of multidrug resistance. J Cancer Res Clin Oncol 121: R1-R1, 1995.

201.Berenson JR, Crowley JJ, Grogan TM, Zangmeister J, Briggs AD, Mills GM, Barlogie B and Salmon SE: Maintenance therapy with alternate-day prednisone improves survival in multiple myeloma patients. Blood 99: 3163-3168, 2002.

202. Urashima M, Chen BP, Chen S, Pinkus GS, Bronson RT, Dedera DA, Hoshi Y, Teoh G, Ogata A, Treon SP, et al: The development of a model for the homing of multiple myeloma cells to human bone marrow. Blood 90: 754-765, 1997. 
203. Brown R, Suen H, Favaloro J, Yang S, Ho PJ, Gibson J and Joshua D: Trogocytosis generates acquired regulatory $\mathrm{T}$ cells adding further complexity to the dysfunctional immune response in multiple myeloma. OncoImmunology 1: 1658-1660, 2012.

204. Duffy MJ: Serum tumor markers in breast cancer: Are they of clinical value? Clin Chem 52: 345-351, 2006.

205. Allin KH, Nordestgaard BG, Flyger H and Bojesen SE: Elevated pre-treatment levels of plasma C-reactive protein are associated with poor prognosis after breast cancer: A cohort study. Breast Cancer Res 13: R55, 2011.

206. Guo L, Abraham J, Flynn DC, Castranova V, Shi X and Qian Y: Individualized survival and treatment response predictions for breast cancers using phospho-EGFR, phospho-ER, phospho-HER 2/neu, phospho-IGF-IR/In, phospho-MAPK, and phospho-p70S6K proteins. Int J Biol Markers 22: 1-11, 2007.

207. Sargent DJ, Conley BA, Allegra C and Collette L: Clinical trial designs for predictive marker validation in cancer treatment trials. J Clin Oncol 23: 2020-2027, 2005.

208. Kumar G, Lau H and Laskin O: Lenalidomide: In vitro evaluation of the metabolism and assessment of cytochrome P450 inhibition and induction. Cancer Chemother Pharmacol 63 1171-1175, 2009.

209. Lampen A, Zhang Y, Hackbarth I, Benet LZ, Sewing KF and Christians U: Metabolism and transport of the macrolide immunosuppressant sirolimus in the small intestine. J Pharmacol Exp Ther 285: 1104-1112, 1998.

210. Sattler M, Guengerich FP, Yun CH, Christians U and Sewing KF: Cytochrome P-450 3A enzymes are responsible for biotransformation of FK506 and rapamycin in man and rat. Drug Metab Dispos 20: 753-761, 1992.
211. Joshua DE, Brown RD and Gibson J: Multiple myeloma: Why does the disease escape from plateau phase? Br J Haematol 88: 667-671, 1994.

212. Fung KL and Gottesman MM: A synonymous polymorphism in a common MDR1 (ABCB1) haplotype shapes protein function. Biochim Biophys Acta 1794: 860-871, 2009.

213. Hoffmeyer S, Burk O, von Richter O, Arnold HP, Brockmöller J, Johne A, Cascorbi I, Gerloff T, Roots I, Eichelbaum M, et al: Functional polymorphisms of the human multidrug-resistance gene: Multiple sequence variations and correlation of one allele with P-glycoprotein expression and activity in vivo. Proc Natl Acad Sci USA 97: 3473-3478, 2000.

214. Dumontet C, Landi S, Reiman T, Perry T, Plesa A, Bellini I, Barale R, Pilarski LM, Troncy J, Tavtigian S, et al: Genetic polymorphisms associated with outcome in multiple myeloma patients receiving high-dose melphalan. Bone Marrow Transplant 45: 1316-1324, 2010.

215. Maggini V, Buda G, Martino A, Presciuttini S, Galimberti S, Orciuolo E, Barale R, Petrini M and Rossi AM: MDR1 diplotypes as prognostic markers in multiple myeloma. Pharmacogenet Genomics 18: 383-389, 2008.

216. Natarajan K, Xie Y, Baer MR and Ross DD: Role of breast cancer resistance protein (BCRP/ABCG2) in cancer drug resistance. Biochem Pharmacol 83: 1084-1103, 2012.

217. Dispenzieri A, Kyle R, Merlini G, Miguel JS, Ludwig H, Hajek R, Palumbo A, Jagannath S, Blade J, Lonial S, et al; International Myeloma Working Group: International Myeloma Working Group guidelines for serum-free light chain analysis in multiple myeloma and related disorders. Leukemia 23: 215-224, 2009. 